ARTICLE

DOI: $10.1038 / s 41467-017-01120-3$

\title{
Odd skipped-related 1 identifies a population of embryonic fibro-adipogenic progenitors regulating myogenesis during limb development
}

Pedro Vallecillo-García (10 1,2, Mickael Orgeur ${ }^{1,2,3,4}$, Sophie vom Hofe-Schneider (10 1, Jürgen Stumm ${ }^{1,2}$, Verena Kappert ${ }^{1,2}$, Daniel M. Ibrahim (10 2, Stefan T. Börno ${ }^{2}$, Shinichiro Hayashi ${ }^{5,6}$, Frédéric Relaix ${ }^{5,6}$, Katrin Hildebrandt ${ }^{7}$, Gerhard Sengle ${ }^{7}$, Manuel Koch (1) ${ }^{7}$, Bernd Timmermann², Giovanna Marazzi ${ }^{8,9}$, David A. Sassoon ${ }^{8,9}$, Delphine Duprez (1) ${ }^{3,4}$ \& Sigmar Stricker (1D 1,2

Fibro-adipogenic progenitors (FAPs) are an interstitial cell population in adult skeletal muscle that support muscle regeneration. During development, interstitial muscle connective tissue (MCT) cells support proper muscle patterning, however the underlying molecular mechanisms are not well understood and it remains unclear whether adult FAPs and embryonic MCT cells share a common lineage. We show here that mouse embryonic limb MCT cells expressing the transcription factor Osr1, differentiate into fibrogenic and adipogenic cells in vivo and in vitro defining an embryonic FAP-like population. Genetic lineage tracing shows that developmental $\mathrm{Osr}^{+}$cells give rise to a subset of adult FAPs. Loss of Osr1 function leads to a reduction of myogenic progenitor proliferation and survival resulting in limb muscle patterning defects. Transcriptome and functional analyses reveal that $\mathrm{Osr}^{+}{ }^{+}$cells provide a critical pro-myogenic niche via the production of MCT specific extracellular matrix components and secreted signaling factors.

\footnotetext{
${ }^{1}$ Institute for Chemistry and Biochemistry, Freie Universität Berlin, D-14195 Berlin, Germany. ${ }^{2}$ Max Planck Institute for Molecular Genetics, D-14195 Berlin, Germany. ${ }^{3}$ Sorbonne Universités, UPMC Univ Paris 06, CNRS UMR7622, IBPS-Developmental Biology Laboratory, F-75005 Paris, France. ${ }^{4}$ Inserm U1156, IBPS-Developmental Biology Laboratory, F-75005 Paris, France. ${ }^{5}$ Inserm, IMRB U955-E10, F-94000 Créteil, France. ${ }^{6}$ Université Paris Est, Faculté de médecine, Créteil, \& Ecole Nationale Vétérinaire d'Alfort, F-94700 Maison Alfort, France. ${ }^{7}$ Institute for Biochemistry, University of Cologne, D-50931 Cologne, Germany. ${ }^{8}$ Stem Cells and Regenerative Medicine, ICAN-UMRS 1166, Université de Pierre et Marie Curie, Sorbonne Universités, F-75634 Paris, France. ${ }^{9}$ ICAN, Institute of Cardiometabolism and Nutrition, F-75634 Paris, France. Mickael Orgeur and Sophie vom Hofe-Schneider contributed equally to this work. Correspondence and requests for materials should be addressed to S.S. (email: sigmar.stricker@fu-berlin.de)
} 
S keletal muscles are composed of cells of different developmental origins. In vertebrate limbs, muscle fibres as well as muscle stem cells (termed satellite cells in the adult) originate from the somitic mesoderm ${ }^{1-3}$, while muscle connective tissue (MCT) originates from the lateral plate mesoderm ${ }^{1,2}$. A mutual interdependence and cross-talk between both cell types exist during developmental and adult regenerative myogenesis. During development the myogenic progenitors migrate from the somites to the nascent limb buds, where they form initial premuscle masses that amplify and then subdivide into individual muscles with each muscle having an individual shape and size ${ }^{4,5}$. It is widely accepted that vertebrate myogenic cells do not contain intrinsic information that govern their place and time of differentiation ${ }^{6,7}$. Instead, there is long-standing evidence that limb muscle patterning is mediated by extrinsic signals from local lateral plate mesoderm derived cells ${ }^{8-10}$. This non-cell autonomous function is most likely mediated by MCT cells providing local but still undefined cues for myogenic cell proliferation, differentiation, survival and local migration ${ }^{11-13}$.

MCT is often used as a collective term for different interstitial cell types, i.e. cells that can be found between the myofibres in adult muscle. Muscle interstitial cells comprise $\mathrm{Tcf} 4^{+}$connective tissue fibroblasts that originate from lateral plate mesoderm ${ }^{12}, 14$, but also diverse populations of mesenchymal progenitor cells have been defined ${ }^{15-18}$. The exact relationship between connective tissue fibroblasts and interstitial mesenchymal progenitors is unclear and it was proposed that they largely overlap ${ }^{14,} 19$. Amongst these progenitors, a population of non-myogenic fibroadipogenic progenitors (FAPs) was identified that rapidly expand upon muscle injury and promote myogenesis in vitro ${ }^{20}$, but also give rise to fibrosis and fatty infiltration in diseases ${ }^{21,22}$. The promyogenic function ascribed to FAPs during adult muscle regeneration is an intriguing parallel to the function lateral platederived MCT progenitors play during embryonic myogenesis. Whether or not FAPs and developmental MCT progenitors are related and what molecular mechanisms contribute to their promyogenic function is mostly unknown.

In this study we show that the transcription factor Odd skipped-related 1 (Osr1) marks a subset of embryonic MCT cells that constitute a developmental FAP-like population, which supports embryonic myogenesis and is also a developmental source of adult muscle interstitial FAPs. We further show that loss of Osr1 function during limb development leads to a marked decrease in myogenic progenitor expansion and muscle patterning defects. Consistent with these observations, we show that Osr1 lies upstream of a large number of genes that control muscle connective tissue function.

\section{Results}

Osr1 marks a subpopulation of limb MCT cells. Osr1 is expressed in MCT cells in chick embryos and is involved in chick connective tissue differentiation ${ }^{23}$, 24 . In mice, Osr1 expression can be followed via an eGFP-IRES-CreERt2 knock-in allele $\left(O s r 1^{G C E}\right)^{25}$ and was found in embryonic limb mesenchyme correlating with areas of myogenic differentiation between E11.5 and E13.5 (Fig. 1a-e, Supplementary Fig. 1a). Apart from the limbs, $\mathrm{Osr}^{+}$interstitial cells were also observed in and surrounding other muscles as the shoulder girdle muscles and superficial as well as deep muscles of the back (Supplementary Fig. 1b). Not all muscles harbour Osr1 ${ }^{+}$interstitial cells; low GFP signal was seen, for example, in intercostal muscles (Supplementary Fig. 1b). In addition, the diaphragm and the tongue contained Osrl ${ }^{+}$interstitial cells (Supplementary Fig. 1c). In the limbs, $\mathrm{Osr}^{+}$cells were observed in close association with $\mathrm{Lbxl}^{+}$ and $\mathrm{Pax}^{+}$myogenic progenitors (Fig. 1a, b), closely associated with but distinct from Myod $1^{+}$myoblasts (Fig. 1c) and differentiating myofibres (Fig. 1d). At E14.5, Osr1 ${ }^{+}$cells were found in an interstitial position between myofibres (Fig. 1e). The Osr1-GFP expression pattern was similar to that of Osr1 transcripts (Fig. 1f). Osr1 expression was independent of the presence of myogenic cells as shown by normal Osr1 expression in muscleless limbs of Pax3 ${ }^{G F P / G F P}$ mutant mice (Fig. If, Supplementary Fig. 2).

Freshly FACS-isolated $\mathrm{Osrl}^{+}$cells from E13.5 Osr1 ${ }^{\mathrm{GCE} /+}$ embryonic limbs (Fig. 1g) expressed fibroblastic markers, including type I Collagen (COL1), PDGFR $\alpha$, Vimentin, type VI Collagen (COL6) and alpha-smooth muscle actin ( $\alpha$ SMA) (Fig. 1h). This fibroblastic signature was maintained in cultures with standard growth medium (Fig. 1i). Consistent with these observations, mRNA-sequencing (RNA-Seq) data from Osr ${ }^{G C E}$ ${ }^{+}$cells revealed that freshly isolated $\mathrm{Osr}^{+}{ }^{+}$cells strongly express genes encoding ECM components characteristic of fibroblasts (Supplementary Table 1). To exclude Osr1 expression in a small subset of myogenic cells or low-level expression in myogenic cells, we FACS-isolated limb mononuclear cells divided into Osr1expressing $\left(\mathrm{GFP}^{+}\right)$and Osr1-negative $\left(\mathrm{GFP}^{-}\right)$populations (Supplementary Fig. 3a) and analysed myogenic marker expression after cytospin. Myf5 ${ }^{+}$or Myogenin ${ }^{+}$cells were only found in the GFP $^{-}$FACS fraction, anti-GFP antibody labelling did not identify any $\mathrm{GFP}^{+} / \mathrm{Myf5}^{+}$or $\mathrm{GFP}^{+} /$Myogenin ${ }^{+}$cells (Supplementary Fig. 3b). Altogether, this establishes that Osrl is a marker for a subpopulation of mouse limb MCT cells.

Osr1 $^{+}$MCT population partially overlaps with Tcf4. Tcf4 (Tcf7l2) is a recognised marker for embryonic MCT cells ${ }^{11,12}$, however less than $60 \%$ of FACS-isolated Osr $1^{+}$cells showed Tcf4 expression at E13.5 (Fig. 1h, i), indicating that limb MCT is a heterogeneous entity that contains distinct subpopulations. We then compared the expression of Osr1 and Tcf4 in E11.5 and E13.5 hindlimbs (Fig. 2a, b). At E11.5 Osr1 and Tcf4 were expressed in limb mesenchyme flanking the cartilaginous condensation of the humerus (Fig. 2a). The Osr1 or Tcf4 expression domains partially overlapped, cells expressing both transcription factors were found, but also cells expressing either Osr1 or Tcf4 exclusively (Fig. 2a). Osr1 was also expressed in mesenchyme flanking the scapula condensation, where Tcf4 was not expressed (Fig. 2a). At E13.5, Osr1 and Tcf4 showed distinct expression patterns in hindlimbs, although with areas of coexpression (Fig. 2b). Osr1 was generally found more towards the periphery, while Tcf4 was prevalent in central regions. The biceps femoris muscle exclusively harboured $\mathrm{Osr}^{+}$cells, the flexor digitorum longus muscle exclusively harboured $\mathrm{Tcf}_{4}{ }^{+}$cells. Interstitial cells coexpressing Osr1 and Tcf4 were, for example, observed in the gastrocnemius and tibialis anterior muscles. The gastrocnemius interstitial cells showed higher Osrl, the tibialis anterior interstitial cells higher Tcf4 expression at this stage (Fig. 2b).

We next analysed the relationship of Osr1 and Tcf4 expression at later developmental stages. To this end we isolated foetal (E18.5) Osr1-expressing and Osr1-negative $\left(\mathrm{GFP}^{+}\right.$and $\left.\mathrm{GFP}^{-}\right)$ interstitial cells from dissected hindlimb muscles by FACS (CD45 ${ }^{-} ; \mathrm{CD} 31^{-} ;$Ter119-; $\alpha 7$-integrin ${ }^{-}$to remove satellite cells) and analysed Tcf4 expression in $\mathrm{GFP}^{+}$and $\mathrm{GFP}^{-}$fractions via immunolabelling after cytospin. The majority of the $\mathrm{GFP}^{+}$cells were $\mathrm{Tcf}_{4}^{+}(72,9 \%)$. The $\mathrm{GFP}^{-}$fraction harboured apparently less $\mathrm{Tcf}^{+}$cells $(64,3 \%)$. The low overlap of both markers at E13.5 (Fig. 1h, Fig. 2b) suggests that Osr $1^{+}$cells acquire Tcf4 expression during development. In addition, the majority of the $\mathrm{GFP}^{+}$cells were positive for PDGFR $\alpha(72,1 \%)$, while the $\mathrm{GFP}^{-}$pool was clearly reduced for PDGFR $\alpha^{+}$cells (43,7\%; Fig. 2c). Of all $\mathrm{Tcf}^{+}$ cells (i.e. within $\mathrm{GFP}^{+}$and $\mathrm{GFP}^{-}$populations), $66,4 \%$ expressed PDGFR $\alpha$ (Fig. 2c). This establishes that neither Tcf4 nor Osr1 are 
a

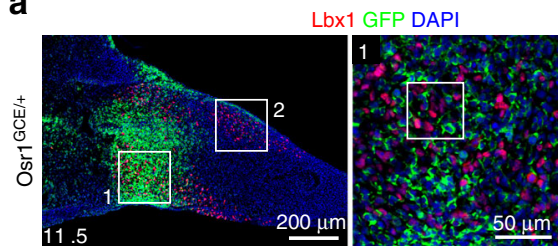

b

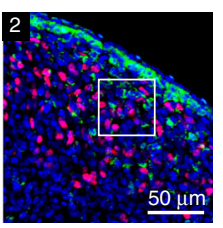

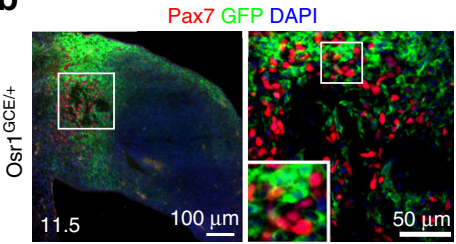

c

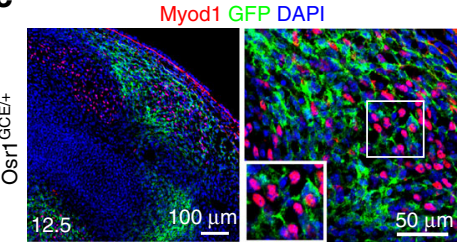

d

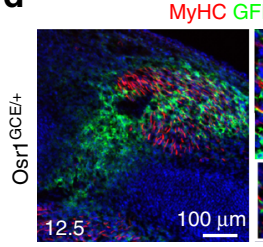

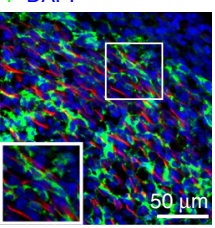

e

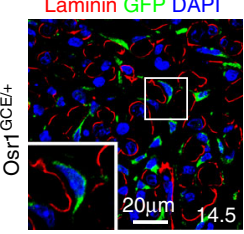

f
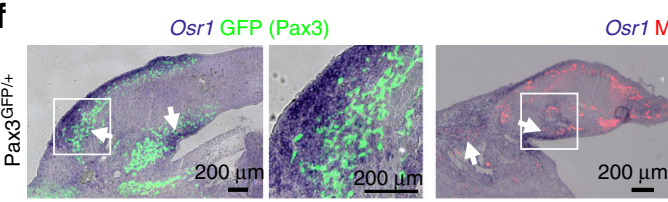

Osr1 Myod1
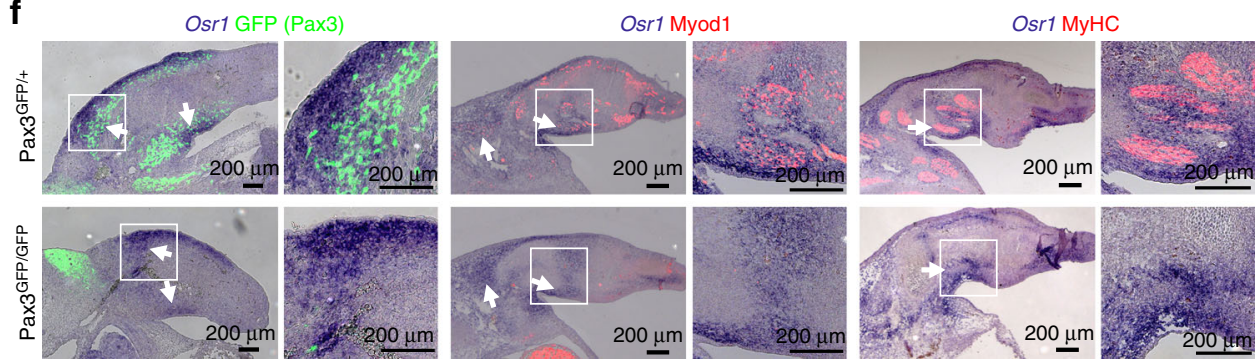

g
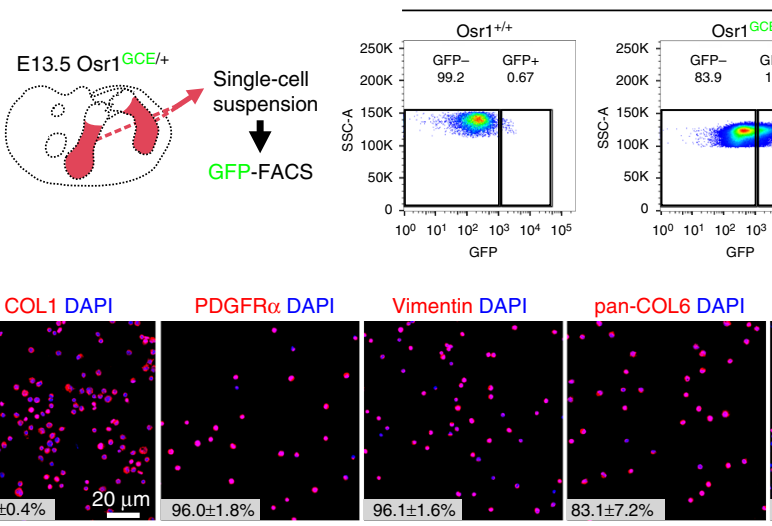

$\mathrm{Sr}^{\mathrm{GCE} /+}$

h
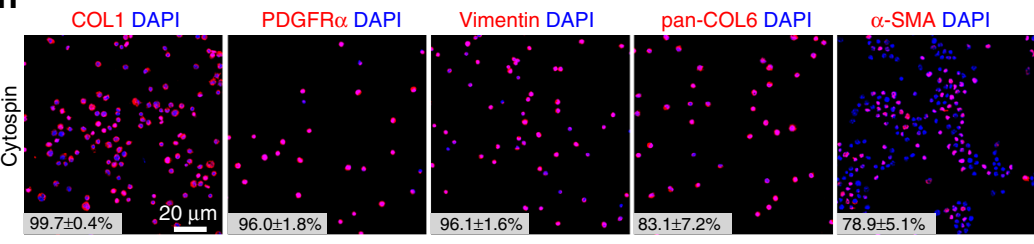

Tcf4 DAPI
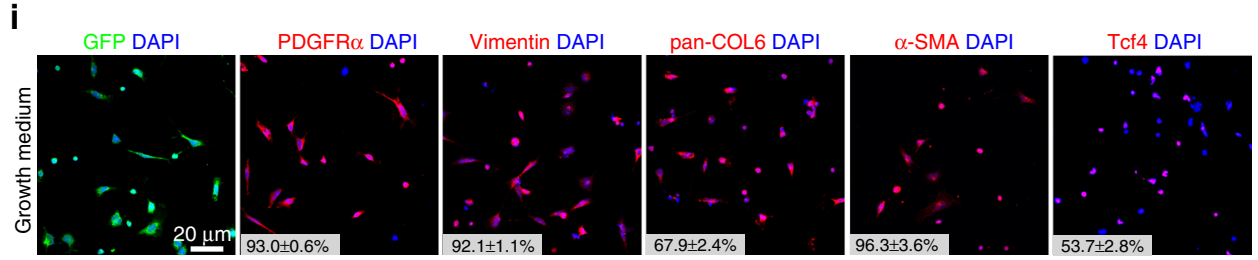

Fig. 1 Osr1 is expressed in limb mesenchymal cells associated with myogenic cells and labels MCT cells. a-e Osr1 expression was assessed by immunolabelling for GFP on Osr $7^{\mathrm{GCE} /+}$ embryos at the indicated stages. Osr1 ${ }^{+}$cells are found interstitial to $\mathrm{Lbx} 1^{+}$, Pax $7^{+}$and $\mathrm{MyoD}^{+}$myogenic progenitors and interstitial to developing myofibres labelled either for Myosin heavy chain (MyHC) or Laminin. Note that in some developing muscles Osr1 ${ }^{+}$cells are abundant, while being scarce in others. Boxed regions (numbered in a) are shown in the panels to the right of overview images and are magnifications of the area. f Osr1 expression was analysed by in situ hybridization to sections of muscleless limbs of E11.5 (left), 12.5 (middle) and 13.5 (right) Pax3 mutant embryos. The overall expression pattern of Osr1 is similar in limbs of Pax $3^{G F P /+}$ and Pax3 $3^{\text {GFP/GFP }}$ embryos. Arrows highlight strong Osr1 expression observed in control and muscleless limbs. Boxed regions are shown in the panels to the right of overview images and are magnifications of the area. $\mathbf{g}$ Schematic depiction of limb Osr1 ${ }^{+}$cell isolation procedure and examples of FACS plots. $\mathbf{h}$ Expression of fibroblastic markers in freshly FACS-isolated Osr1 ${ }^{+}$cells subjected to cytospin. $(n=3)$. $\mathbf{i}$ Osr $1^{+}$cells cultured in growth medium maintained the expression of fibroblastic markers $(n=3)$. Insets in $\mathbf{h}, \mathbf{i}$ are percentage of $\mathrm{COL}_{1}^{+}, \mathrm{PDGFR \alpha}^{+}$, Vimentin $^{+}, \mathrm{Pan}-\mathrm{COL} 6^{+}, \alpha \mathrm{SMA}^{+}$and $\mathrm{Tcf}_{4}^{+}$cells among the Osr $1^{+}$cell population. Values represent mean \pm s.e.m. $\mathrm{N}$-numbers indicate biological replicates, i.e. samples from different specimen 
a
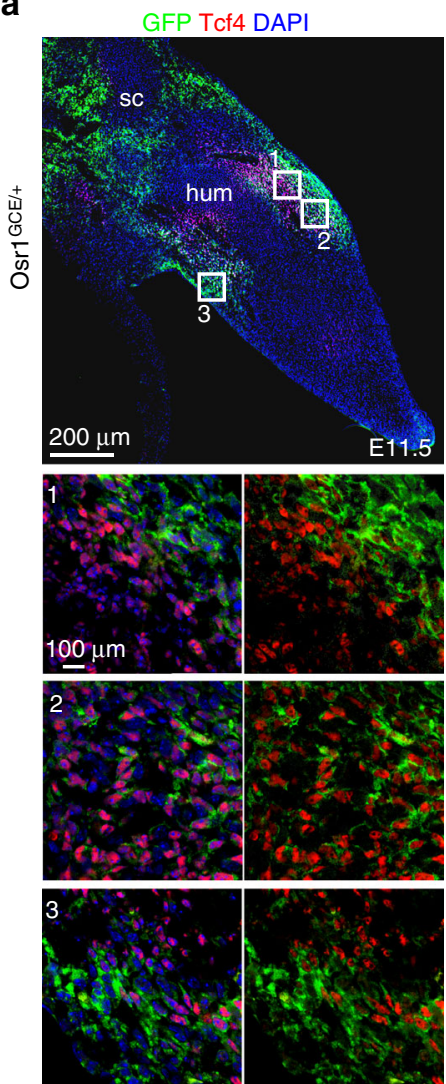

b

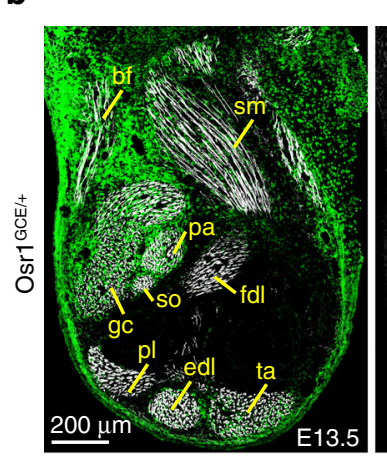

GFP Tcf4 MyHC
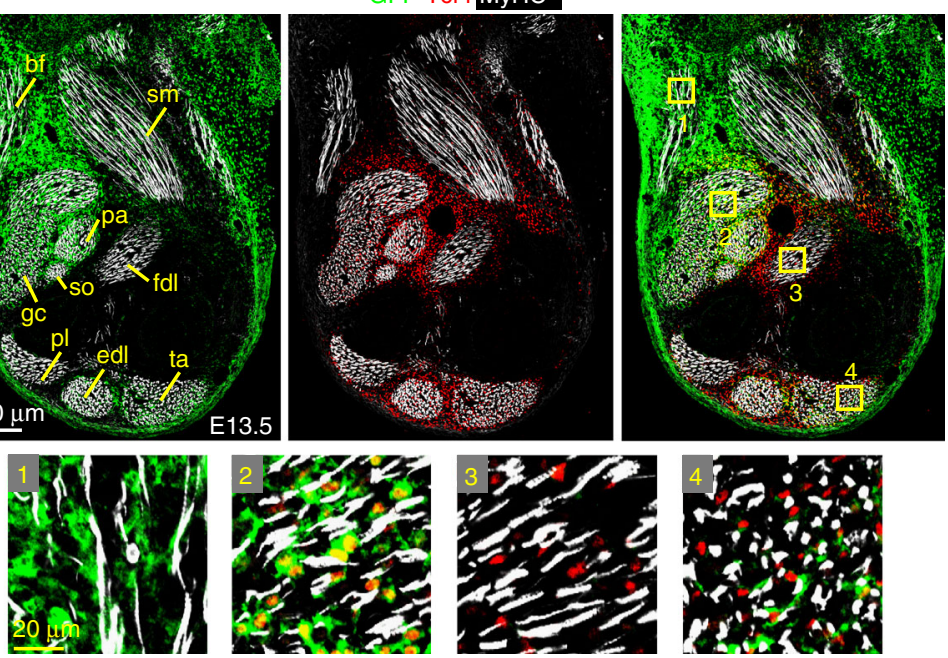

C

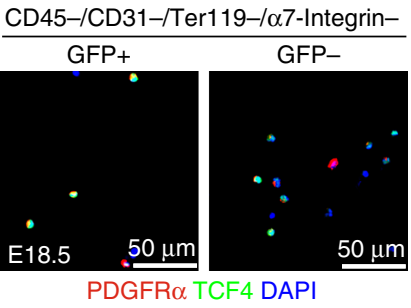

Fig. 2 Osr1 and Tcf4 identify distinct and common MCT cells. a, b Osr1 expression was assessed by immunolabelling for GFP on E11.5 and E13.5 Osr1GCE/+ embryos. Boxed regions are shown in the numbered panels below and are magnifications of the area. a At E11.5 Osr1 is expressed in limb mesenchyme at the level of the humerus condensation overlapping with Tcf4. Tcf4 is expressed towards the centre and Osr1 towards the periphery of the limb. $\mathbf{b}$ At E13.5 Osr1 is expressed in limb mesenchyme in the periphery and encompassing the biceps femoris (bf), gastrocnemius (gc), soleus (so), plantaris (pa), semimembranosus (sm), peroneus longus ( $\mathrm{pl}$ ), extensor digitorum longus (edl) and tibialis anterior (ta) muscles. Tcf4 is expressed in central areas of the limb, where it is exclusive in the flexor digitorum longus ( $\mathrm{fdl}$ ) muscle, and within and surrounding the edl and ta muscles. c E18.5 limb muscle interstitial cells were FACS-isolated as indicated and separated into Osr7-expressing and Osr7-negative (GFP ${ }^{+}$and $\mathrm{GFP}^{-}$) populations. Cytospun cells were labelled for Tcf4 and PDGFR $\alpha$. Quantification showing the percentages of PDGFR $\alpha^{+}$and Tcf4 $4^{+}$cells in $\mathrm{GFP}^{+}$or $\mathrm{GFP}^{-}$populations is shown below. Percentage of PDGFR $\alpha$ cells in all Tcf4 cells was counted in both GFP' and GFP-populations $(n=3)$. Values represent mean \pm s.e.m $(n=3)$. N-numbers indicate biological replicates, i.e. samples from different specimen

comprehensive MCT cell markers, but indeed appear to identify region-specific subpopulations of MCT in development.

Osr1 $^{+}$cells are developmental fibro-adipogenic progenitors. Limb lateral plate derived cells are a heterogeneous population exhibiting multiple differentiation potentials. We therefore analysed the differentiation potential of the $\mathrm{Osrl}^{+}$cell population. FACS-isolated $\mathrm{Osr}^{+}$cells exposed to fibrogenic, adipogenic, chondrogenic, osteogenic or myogenic conditions in vitro, displayed robust fibrogenic and adipogenic differentiation, whereas $\mathrm{Osr}^{+}$cells displayed very low chondrogenic and no detectable osteogenic or myogenic potentials (Fig. $3 \mathrm{a}$ ). To analyze Osr1 ${ }^{+}$cell differentiation in vivo, we pulsed Osr ${ }^{\mathrm{GCE} /+} ; \mathrm{R} 26 \mathrm{R}^{\mathrm{mTmG}}$ embryos with a single dose of Tamoxifen (TAM) at E11.5 or E13.5 followed by analysis after organogenesis (E18.5). This in vivo genetic $\mathrm{Osr}^{+}$cell lineage tracing showed a contribution of $\mathrm{Osr}^{+}$cell progeny in limb muscle interstitial regions and dermis at E18.5 (Fig. 3b, Supplementary Fig. 4a). Consistent with in vitro adipogenic differentiation (Fig. 3a), $\mathrm{Osrl}^{+}$cell progeny were observed in subcutaneous white adipose tissue in vivo (Fig. 3b, Supplementary Fig. 4a).

As shown above, specific muscles harbour different amounts of $\mathrm{Osr1}^{+}$cells (Fig. 2b). We thus analysed the contribution of E11.5
$\mathrm{Osr}^{+}$cells to $\mathrm{PDGFR}^{+}$and $\mathrm{Tcf}^{+}$interstitial cells in the gastrocnemius muscle as an example for high Osr1 expression, and the tibialis anterior as an example for lower Osr1 expression. As expected, Osr1 descendants labelled by a single TAM dosage at E11.5 contributed stronger to $\mathrm{PDGFR} \alpha^{+}$or $\mathrm{Tcf}^{+}$interstitial cells in gastrocnemius than tibialis anterior (Fig. 3c). Taken together, our data reveal that $\mathrm{Osr}^{+}$cells represent spatially allocated mesenchymal progenitors with fibrogenic and adipogenic fates during development resembling adult muscle interstitial FAPs ${ }^{20,21}$

Adult mouse FAPs are characterized by expression of the surface markers Scal $(\mathrm{Ly} 6 \mathrm{~A} / \mathrm{E})^{20}$ or PDGFR $\alpha^{21,22}$. PDGFR $\alpha$ was also used for FAP selective isolation from human muscles ${ }^{26}$. In addition to these markers, adult FAPs share CD34 with satellite cells ${ }^{20}$ and CD29, CD90 and CD166 with mesenchymal stem cells (MSCs) 21,26 . FAPs were thus proposed to constitute a muscle-specific and lineage-restricted form of $\mathrm{MSC}^{16}$, although this relation awaits clarification. To further elucidate the relationship of embryonic (E13.5) Osr1 $^{+}$cells with adult FAPs and MSCs, we analysed their surface marker profile. E13.5 Osr1 ${ }^{+}$cells were mostly positive for PDGFR $\alpha$ (Fig. 1h, Supplementary Fig. 5a, b). Osr1 ${ }^{+}$cells were positive for CD29, CD166 and mostly negative for CD90. In addition, $\mathrm{Osr}^{+}$cells were positive for the MSC markers CD73, 
a

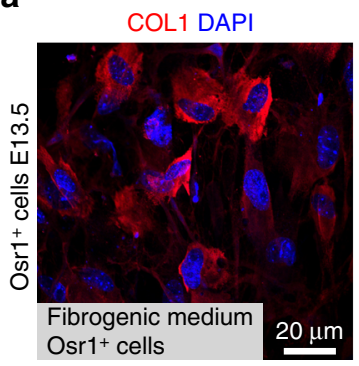

b
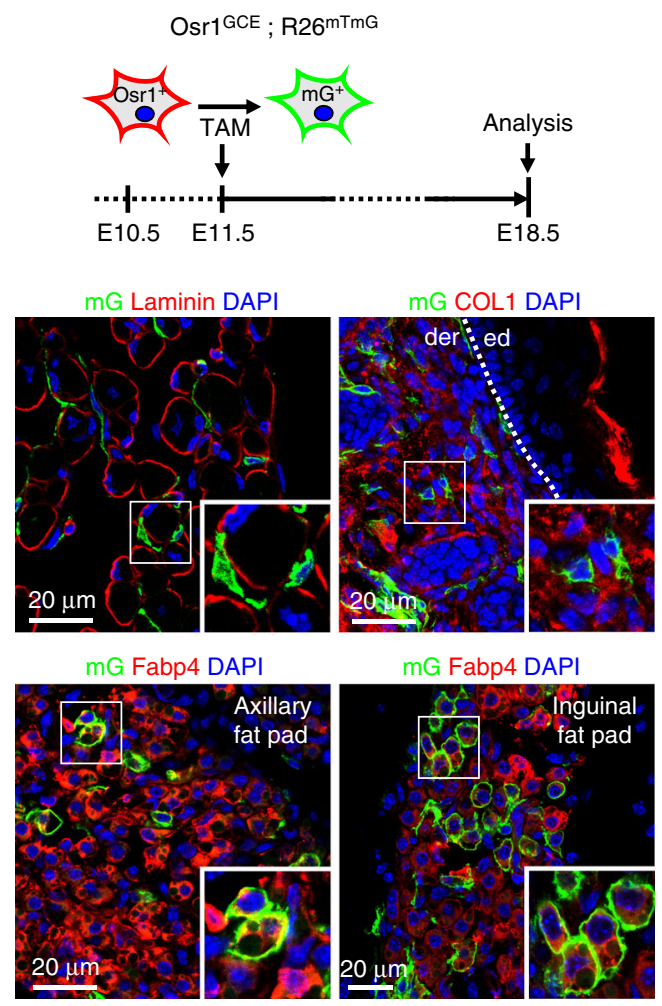

Alcian blue

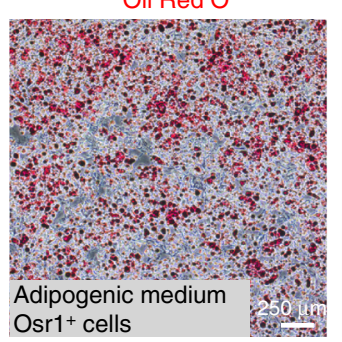

Chondrogenic medium $500 \mu \mathrm{m}$
Osr1+cells

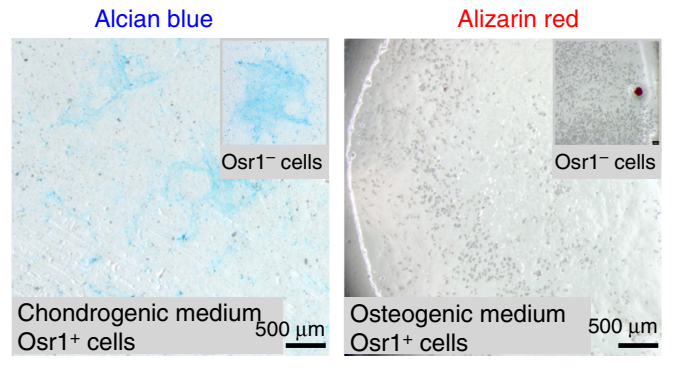

Alizarin red
Myod1 MyHC DAPI

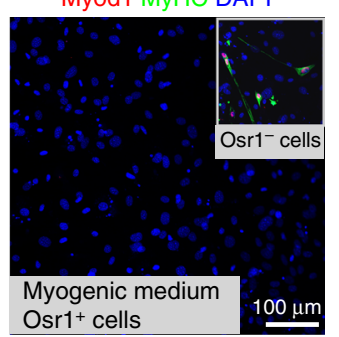

C
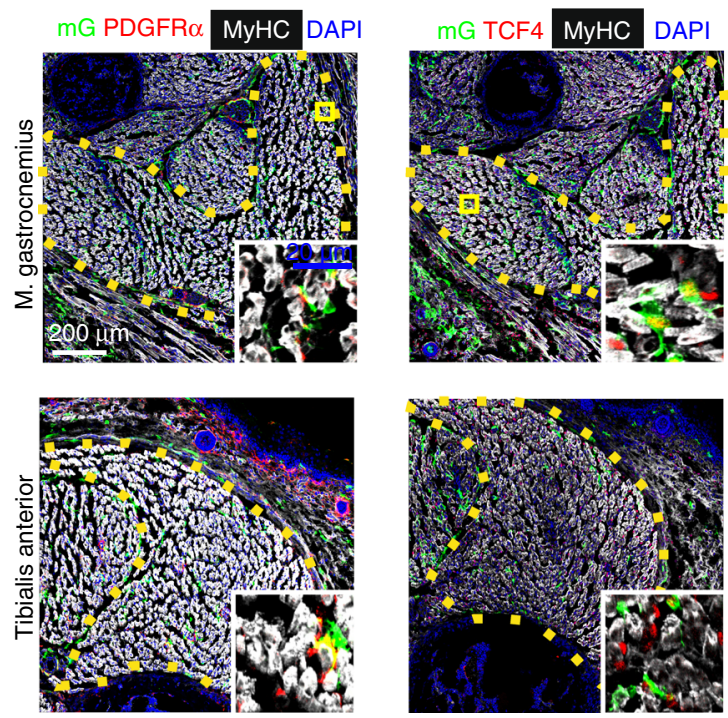

Gastrocnemius Tibialis anterior

PDGFR $\alpha+$ cells from Osr1 lineage

$\bigcup_{ \pm 1.95 \%}^{46.79 \%}$

$25.15 \%$

$\pm 3.92 \%$

TCF4+ cells from Osr1 lineage

(D) $\begin{aligned} & 10.93 \% \\ & \pm 0.53 \%\end{aligned}$

Fig. $3 \mathrm{Osr}^{+}$cells are embryonic fibro-adipogenic progenitors. a Cultures of Osr $1^{+}$cells under fibrogenic, adipogenic, chondrogenic, osteogenic or myogenic conditions. Fibrogenic differentiation was assessed by COL1 immunolabelling, cells exhibited stretched myofibroblast morphology. Adipogenic

differentiation was assessed by Oil Red O staining, chondrogenic and osteogenic differentiation was assessed by Alcian blue and Alizarin red staining, respectively and myogenic differentiation was tested by immunolabelling for Myod1 and MyHC. Osr ${ }^{+}$cells show fibrogenic and adipogenic differentiation, but no osteogenic or myogenic differentiation. GFP- FACS-sorted cells (Osr1 ${ }^{-}$) containing osteo-chondrogenic and myogenic progenitors were used as

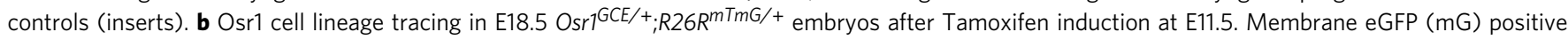
cells represent Osr $1^{+}$cell progeny. Schematic depiction of Osr1 ${ }^{G C E /+} ; R 26 R^{m T m G /+}$-based lineage tracing during development is shown above. Osr $1^{+}$ progenitors give rise to muscle interstitial cells, dermis cells embedded in Collagen type l-rich matrix, and adipocytes immunolabelled for Fatty acid binding

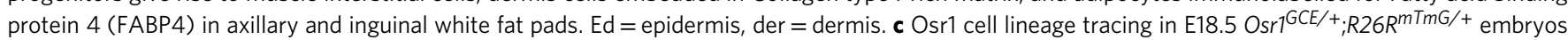

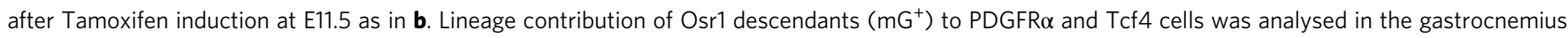
and tibialis anterior muscles. Quantification is shown below $(n=3)$. Values represent mean \pm s.e.m. N-numbers indicate biological replicates, i.e. samples from different specimen

CD105 and CD106, but negative for CD44 and CD146 (Supplementary Fig. 5a). The expression of cell surface markers was in part paralleled by their mRNA abundances in $\mathrm{Osrl}^{+}$cells (Supplementary Table 2). Altogether the Osr1 ${ }^{+}$cell surface marker profile strongly overlaps with that of FAPs and MSCs. However, embryonal $\mathrm{Osrl}^{+}$cells were negative for Scal and CD34 (Supplementary Fig. 5a). This is in line with embryonic expression of Scal confined to the tail and aorta-gonad-mesonephros region ${ }^{27}$, and apparent CD34 expression exclusively in endothelium (Eurexpress database http://www.eurexpress.org) ${ }^{28}$ at that stage.

We then analysed FACS-isolated foetal E18.5 muscle interstitial cells $\left(\mathrm{CD}_{4} 5^{-} ; \mathrm{CD}^{-} ; 1^{-}\right.$Ter119- $\left.{ }^{-} \alpha \mathrm{\text {-integrin }}{ }^{-}\right)$for Sca1 expression and found that a small population of $\mathrm{Scal}^{+}$cells could be detected at this stage (Supplementary Fig. 6a). Intriguingly, Osr1 ${ }^{+}$cells were equally distributed between $\mathrm{Scal}^{-}$and $\mathrm{Sca}^{+}$MCT cells (Supplementary Fig. 6a). It is therefore possible that $\mathrm{Osr}^{+}$cells gain Scal expression over time. We then tested adult $\mathrm{CD}^{-} 5^{-}, \mathrm{CD}^{2} 1^{-}$, Ter119-, a7-integrin ${ }^{-}, \mathrm{Sca}^{+} \mathrm{FAPs}^{20}$ for GFP expression and found very low GFP expression (close to the detection limit) in a small fraction of FAPs, but not in the other interstitial cell populations (Supplementary Fig. 6b). Analysing the expression of Osr1-GFP over time showed that expression of Osr1 declined in muscle interstitial cells soon after birth (Supplementary Fig. 6c). Based on surface marker profiles and in vitro and 
in vivo fibro-adipogenic differentiation potentials of Osr $1^{+}$cells, we conclude that $\mathrm{Osr}^{+}$cells correspond to an embryonic FAPlike population that feeds into fibrous and adipose tissues during development. The acquisition of Scal expression seen in $\mathrm{Osr}^{+}$ cells at E18.5 indicate a direct continuum between $\mathrm{Osrl}^{+}$ developmental cells and adult $\mathrm{Sca}^{+}$FAPs.
Developmental Osr $1^{+}$cells are a source of adult FAPs. We next used long-term genetic lineage tracing to determine whether adult FAPs are the lineage progeny of developmental Osr1 ${ }^{+}$cells. Shortly after birth, interstitial PDGFR $\alpha^{+}$cells still abundantly express Osr1 in muscles like the gastrocnemius (Fig. 4a). Genetic labelling of $\mathrm{Osr}^{+}$cells at birth (TAM at p0 and p1) resulted in
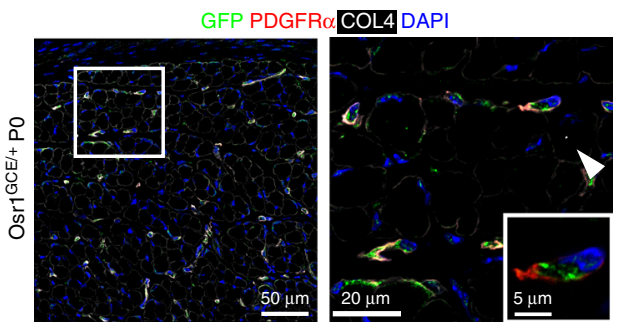

b

Osr1 ${ }^{\mathrm{GCE}} ; \mathrm{R}^{\mathrm{R}} 6^{\mathrm{RLacZ}}$

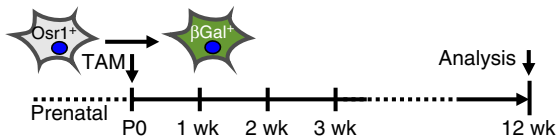

bGal PDGFR $\alpha$ COL4DAPI
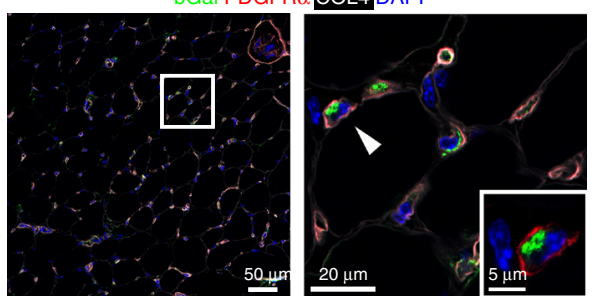

d
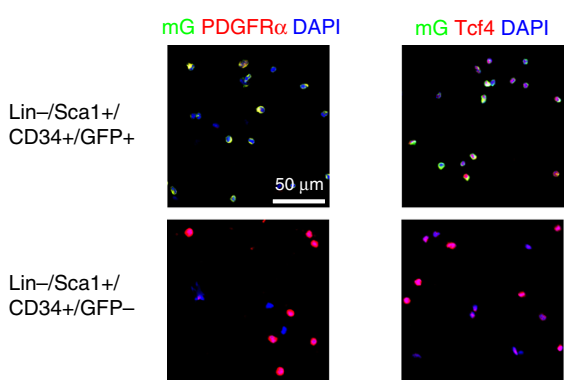

PDGFR $\alpha+$ cells in mGFP+ FAPs

(1) $93.4 \% \pm 3.03 \%$

PDGFR $\alpha+$ cells in mGFP- FAPs

(1) $83.7 \% \pm 1.3 \%$

TCF4+ cells in mGFP+ FAPs

(1) $81.9 \% \pm 4.06 \%$

TCF4+ cells in mGFP- FAPs

( $75.4 \% \pm 1.85 \%$
C
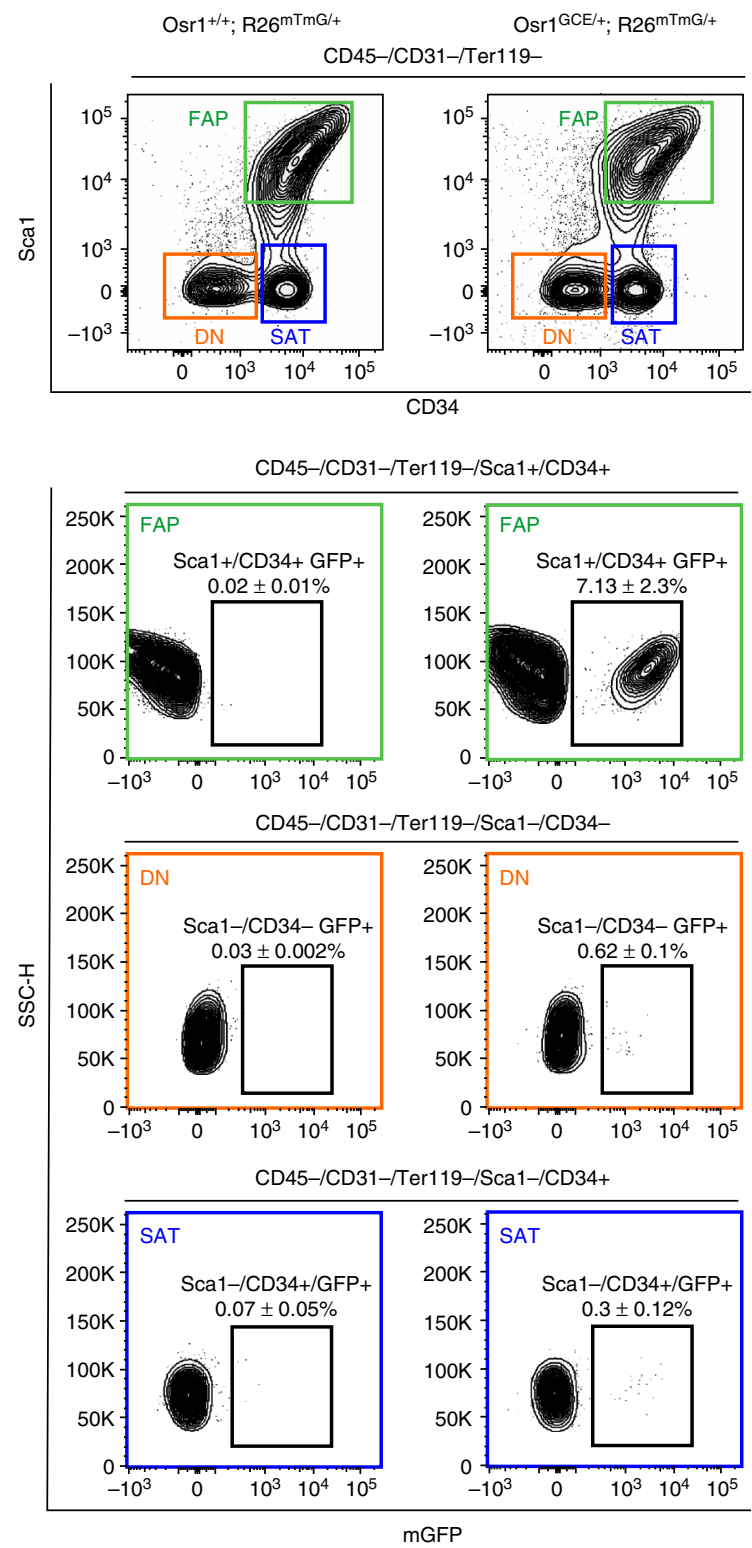

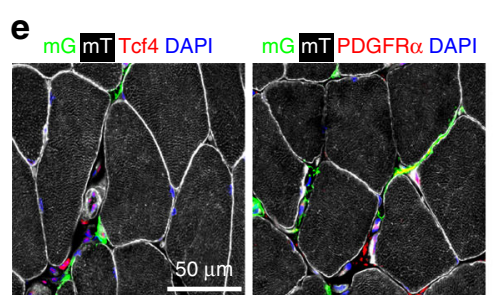

Gastrocnemius

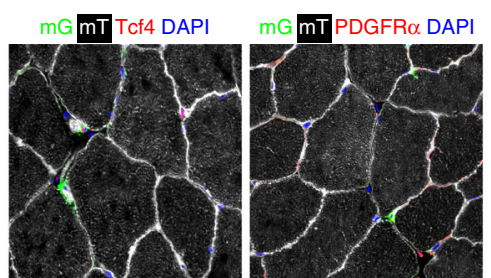

Tibialis anterior

Gastrocnemius

PDGFR $\alpha+$ cells coming from Osr1 lineage

TCF4+ cells coming from Osr1 lineage

$\rightarrow 26.86 \% \pm 2.59 \%$

$D_{18.13 \% \pm 1.39 \%}$
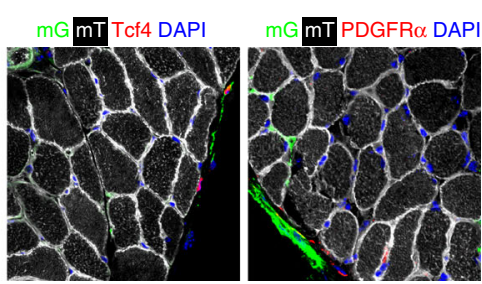

Diaphragm

Diaphragm

( $35.07 \% \pm 4.24 \%$

(24.48\% $\pm 4.78 \%$ 
positive labelling for muscle interstitial PDGFR $\alpha^{+}$cells in the adult (Fig. 4b). Next, we FACS isolated adult FAPs according to Joe et al. ${ }^{20}$ from whole hindlimb muscles of Osr1 ${ }^{\mathrm{GCE} /+} ; \mathrm{R} 26^{\mathrm{mTmG}}$ or, as negative control, $\mathrm{Osr}^{+/+} ; \mathrm{R} 26^{\mathrm{mTmG}}$ animals Tamoxifeninduced at p0/p1. FAPs $\left(\mathrm{CD}_{4} 5^{-} ; \mathrm{CD}_{3} 1^{-} ; \mathrm{Ter} 119^{-} ; \mathrm{Sca}^{+} ; \mathrm{CD} 34^{+}\right)$, satellite cells (CD45 $5^{-}$CD $\left.31^{-} ; \mathrm{Ter} 119^{-} ; \mathrm{Scal}^{-} ; \mathrm{CD} 34^{+}\right)$and osteochondrogenic cells $\left(\mathrm{CD} 45^{-} ; \mathrm{CD} 31^{-} ; \mathrm{Ter} 119^{-} ; \mathrm{Scal}^{-} ; \mathrm{CD} 34^{-}\right)$were analysed for mGFP positive cells. Osr1 progeny was observed exclusively in FAPs, while no lineage progeny was found in satellite cells or osteo-chodrogenic progenitors (Fig. 4c) showing that $\mathrm{Osr}^{+}$progenitors only contribute to the FAP pool. Analysis of cytospun $\mathrm{mGFP}^{+}$and $\mathrm{mGFP}^{-}$FAPs showed that almost all $\mathrm{mGFP}^{+}$cells are PDGFRa ${ }^{+}$. In addition, $\mathrm{mGFP}^{+}$and $\mathrm{mGFP}^{-}$ FAPs harbour a high proportion of $\mathrm{Tcf}^{+}$cells (Fig. $4 \mathrm{~d}$ ). The $\mathrm{mGFP}^{+}$population interestingly appeared enriched for both markers (Fig. 4d). To confirm these findings, the progeny of Osr1 ${ }^{+}$ cells was analysed on sections of gastrocnemius and tibialis anterior muscles and, as an example for a non-limb muscle, the diaphragm. 21\% (TA), 26\% (gastrocnemius) and 35\% (diaphragm) of interstitial PDGFR $\alpha^{+}$cells originated from developmental Osr1 ${ }^{+}$cells pulsed at p0/p1 (Fig. 4e). In addition, Osr1 ${ }^{+}$ progenitors also contributed to different extent to $\mathrm{Tcf}^{+}$cells (Fig. 4e). This correlates with the embryonic lineage tracing results obtained for the TA and gastrocnemius muscles at E18.5 (Fig. 3c) and suggests that the level of Osr1 ${ }^{+}$cell contribution to adult FAPs in individual muscles is reflected by the developmental Osr1 expression pattern. Altogether, this establishes that adult FAPs derive, at least in part, from developmental Osr $1^{+}$cells.

Osr1 regulates embryonic myogenesis. Given the supportive function of adult FAPs in regenerative myogenesis and the noncell autonomous function ascribed to limb MCT cells during muscle development, we asked whether Osr $1^{+}$FAP-like cells have a similar supportive function during embryonic myogenesis. Homozygous Osr $1^{G C E / G C E}$ mutants die between E14.5 and E15.5 due to heart defects ${ }^{29}$, which allowed us to analyse embryonic myogenesis. 3D reconstruction of limb muscles at E14.5 revealed specific muscle patterning defects in Osr1 mutants. In hindlimbs, stylopod muscles were truncated (Fig. 5a). The biceps femoris accessory and posterior head muscles were shortened and myofibres were misoriented compared to wildtype (Fig. 5a). Sections showed a complete absence of myogenic cells in distal areas of the biceps femoris (Fig. 5b), suggesting that muscle progenitors either failed to reach the distal positions or did not survive. In contrast to muscle truncation, scattered ectopic myogenic cells and muscle fibres were observed between muscles (Fig. 5c, Supplementary Fig. 7c, d). Several other muscles of hind- and forelimbs as well as the shoulder and pelvic girdle were variably affected (Supplementary Fig. 7a-e). Overall muscles showing high Osr1 expression such as the biceps femoris (Fig. 5a) or gastrocnemius muscles (Supplementary Fig. 7e) showed clear aberrations, while muscles with low Osr1 expression as the tibialis anterior, extensor digitorum longus or peroneus longus muscles appeared mostly unaffected (Supplementary Fig. 7d).
Myod1 and Myog (Myogenin) expression in E13.5 forelimbs showed defects in size, shape and/or trajectory of individual muscle anlagen in Osr1 mutants (Fig. 5d, Supplementary Fig. 7f). In addition, nascent muscle mass anlagen were less sharply defined as compared to wildtype mice (Fig. 5d). This was already noticeable at earlier stages of development (E11.5), where myogenic cells were present in regions that normally do not contain myogenic cells, and myogenic anlagen displayed a reduced myogenic cell density per area in Osr1 mutants (Supplementary Fig. 8a). This indicates a partial misdistribution of myogenic cells in Osr1 mutants in line with the local lack of myoblasts or local appearance of ectopic myoblasts shown above. Maintenance and amplification of the initial myogenic progenitor pool is essential for correct muscle patterning. In Osrl mutant limbs, the myogenic progenitor pool was reduced at E11.5 and E13.5 compared to respective wildtypes (Fig. 5e, Supplementary Fig. $8 \mathrm{~b}, \mathrm{e}$ ). The number of myogenic progenitors was equally reduced in the proximal as well as dorsal and ventral limb muscle masses at E11.5 indicating that the initial migration step of muscle progenitors was not overtly impaired (Fig. 5e). A measurement of the ratios of $\mathrm{Pax}^{+}$vs. Myod $1^{+}$cells or Pax7 ${ }^{+} / \mathrm{Myod}^{+}$cells vs total Pax $7^{+}$cells showed no difference during early myogenic differentiation in Osr1 mutants at E11.5 (Supplementary Fig. 8b) indicating that the reduction in the number of myogenic cells was not caused by precocious differentiation. Myogenic cells $\left(\mathrm{Lbx}^{+}, \mathrm{Pax}^{+}, \mathrm{Myod}^{+}\right)$of E11.5 (Fig. 5f, Supplementary Fig. 8c, d) and E13.5 (Supplementary Fig. 8f) Osr1 mutants showed a decreased proliferation rate. In addition, myogenic cells showed a significantly increased apoptotic rate in E11.5 Osr1 mutants as compared to wildtype (Fig. 5g). We conclude that a loss of Osr1 function in embryonic FAPs leads to limb muscle patterning defects. These defects are preceded by a reduction of the muscle progenitor pool caused by decreased proliferation and survival of myogenic cells in combination with a misdistribution of myogenic cells. The limb muscle phenotype was not caused by an absence of Osr1 ${ }^{+}$cells (Supplementary Fig. 7g, h).

Osr1 maintains muscle connective tissue identity. To identify Osr1 target genes underlying the non-cell autonomous effect of $\mathrm{Osr}^{+}$cells on muscle formation, we analysed the transcriptome of E13.5 Osr1 ${ }^{G C E / G C E}$ cells vs. Osr1 ${ }^{G C E /+}$ cells. We identified 511 differentially expressed (DE) genes (Fig. 6a). Gene ontology (GO) analysis for "cellular component" highlighted enrichments for "extracellular region" and "extracellular matrix" related genes (Fig. 6b). Consistently, KEGG analysis of all DE genes yielded enrichment for "ECM-receptor interaction" (Supplementary Fig. 9a). Interestingly, genes belonging to the ECM cluster showed a bipartite behaviour with approximately half of the genes being down-regulated or up-regulated (Fig. 6c). Analyses of gene expression using the Eurexpress database ${ }^{28}$ revealed predominant expression of ECM genes that were upregulated in Osr1 deficient cells in cartilage and/or tendons. In accordance, GO analysis of upregulated genes revealed a significant enrichment for "skeletal

Fig. 4 Developmental Osr1 ${ }^{+}$cells are a source for adult FAPs. a Osr1 is expressed in PDGFR $\alpha^{+}$interstitial mesenchymal progenitors at birth (postnatal day PO). b Osr1 cell lineage tracing in adult (P84/12 week) Osr1 ${ }^{G C E /+} ; R 26 R^{\text {LacZ/+ }}$ animals after Tamoxifen induction at PO. Osr1 ${ }^{+}$cell progeny is marked by immunolabelling for beta-Galactosidase (bGal). Perinatal Osr $1^{+}$cells give rise to interstitial PDGFR $\alpha^{+}$FAPs. c Osr1 cell lineage tracing in adult (12 week)

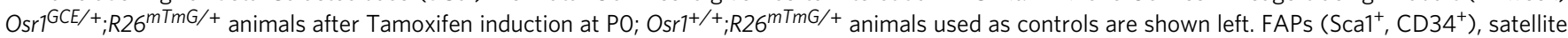
cells (SAT) and double-negaitve cells (DN) were FACS-isolated and analysed for mGFP expression. Only FAPs contained a clearly detectable mGFP ${ }^{+}$ population $(n=3)$. $\mathbf{d} \mathrm{mGFP}^{+}$and $\mathrm{mGFP}^{-}$FAPs isolated as in c were cytospun and analysed for PDGFR $\alpha$ and Tcf4 expression. Quantification is shown below $(n=3)$. e The contribution of pO Osr $1^{+}$cells to muscle interstitial PDGFRo ${ }^{+}$and $\mathrm{Tcf}^{+}{ }^{+}$cells was quantified on sections of $\mathrm{Osr} 7^{G C E /+} ; R 26^{\mathrm{mTmG} /+}$ animals in the indicated muscles. Quantification is shown below $(n=4)$. Values represent mean \pm s.e.m. N-numbers indicate biological replicates, i.e. samples from different specimen 
a
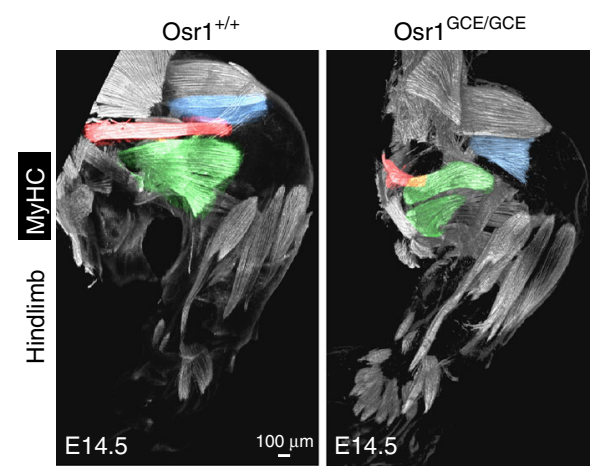

b
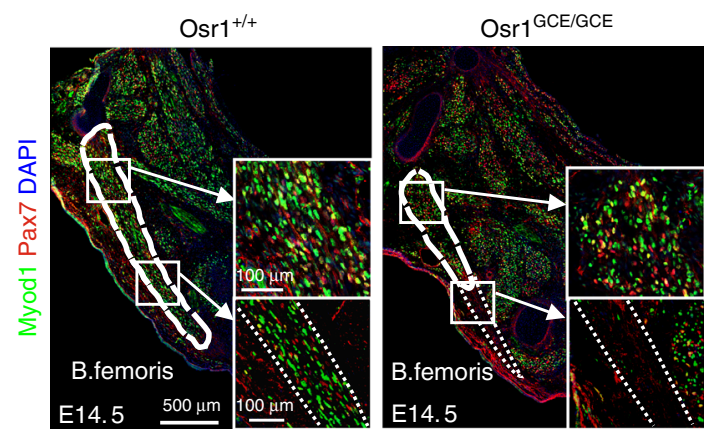

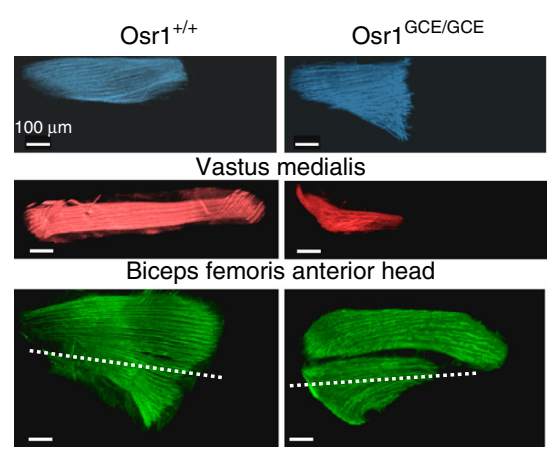

Biceps femoris accessory and posterior head

\section{C}

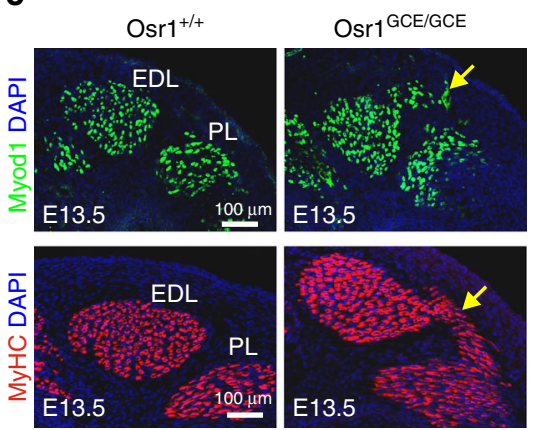

d

$\mathrm{Osr1}^{+/+}$

Osr1 $1^{\mathrm{GCE} / \mathrm{GCE}}$

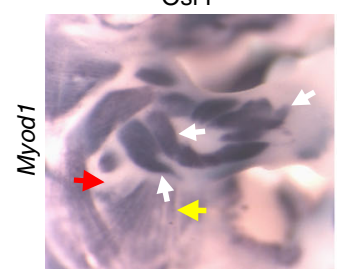

e

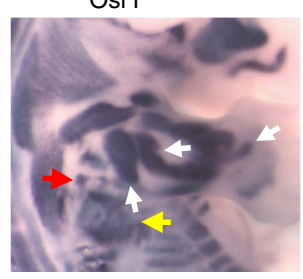

f
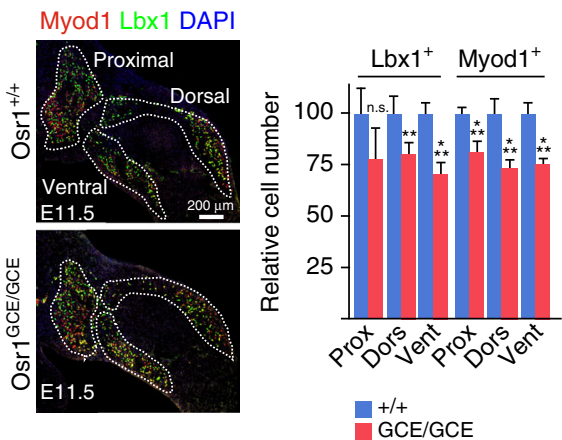

Osr1 ${ }^{+/+}$
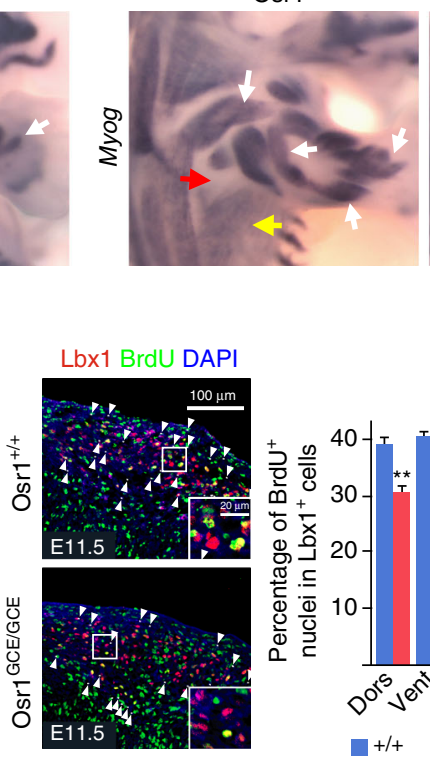

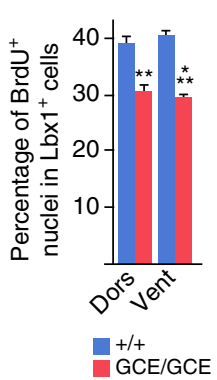

Osr1 ${ }^{\mathrm{GCE} / \mathrm{GCE}}$

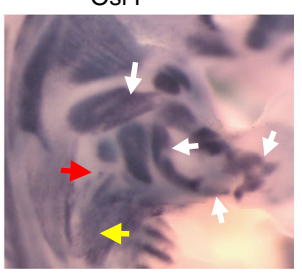

$\mathbf{9}$
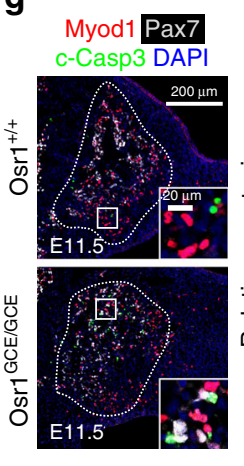

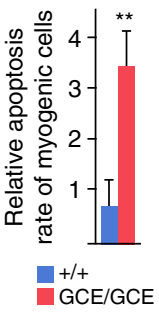

Fig. 5 Limb muscle patterning defects in Osr1-deficient embryos. a Muscle pattern in hindlimbs of E14.5 Osr1 ${ }^{+/+}$and Osr1 ${ }^{\text {GCE } / G C E}$ embryos assessed by whole limb immunolabelling for Myosin heavy chain (MyHC) followed by 3D reconstruction. Affected muscles are highlighted by false colours. Note truncations of several muscles. Scale bars: $100 \mu \mathrm{m}$. b Sections of E13.5 hindlimbs, where the Biceps femoris muscle is highlighted. Section planes are indicated in green muscles ( $\mathrm{a}$, bottom right) by the dashed lines. The distal truncated region of the B. femoris muscle is devoid of myogenic cells in Osr1 mutants highlighted with dashed lines. In the residual B. femoris muscle of Osr1 mutants, myogenic cells appear in disarray (see high magnifications). Analysis was done on serial sections of whole limbs to exclude section artefacts. $\mathbf{c}$ Ectopic Myod1 ${ }^{+}$myoblasts and $\mathrm{MyHC}^{+}$myofibers between the Extensor digitorum longus (EDL) and Peroneus longus (PL) muscles in Osr1 mutants (yellow arrows). d Wholemount in situ hybridization on E13.5 Osr1 ${ }^{+/+}$or Osr TCE/GCE embryos for myogenic markers Myod1 and Myog. Misshaped muscle primordia in limbs (white arrows), disarrayed myofibres in the latissimus dorsi muscle (yellow arrows) and ectopic myoblasts (red arrows) are observed in Osr1 mutants. e Immunolabelling for Lbx1 and Myod1 on E11.5 limb sections shows a decrease in the overall number of myogenic cells in proximal, dorsal and ventral muscle primordia in mutant compared to wt embryos ( $n$

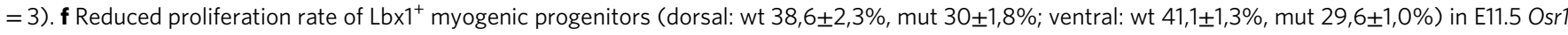
mutants assessed by BrdU labelling $(n=4)$. ( $(\mathbf{g})$ Increased apoptosis in myogenic cells in Osr1 mutants assessed by immunolabelling for cleaved (activated) Caspase 3 (c-Casp3) $\left(n=3\right.$ ). Error bars represent s.e.m. T-test: ${ }^{*}=p<0.05 ;{ }^{\star \star}=p<0.01 ;{ }^{\star \star \star}=p<0.001 . \mathrm{N}$-numbers indicate biological replicates,

i.e. samples from different specimen 
a

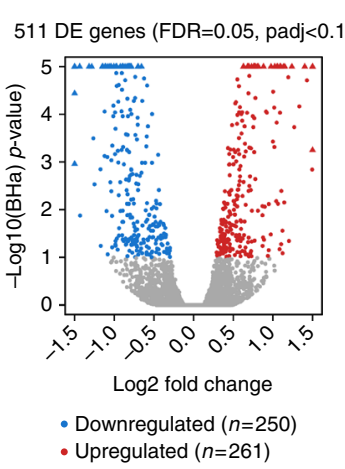

b

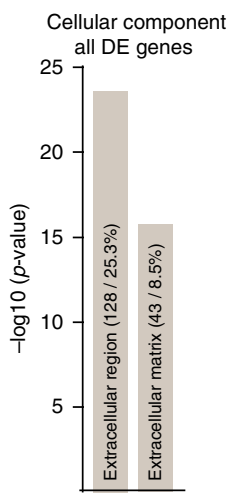

C

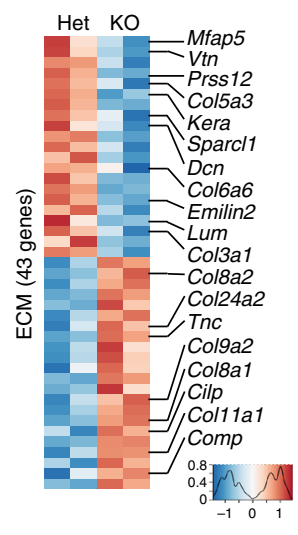

d

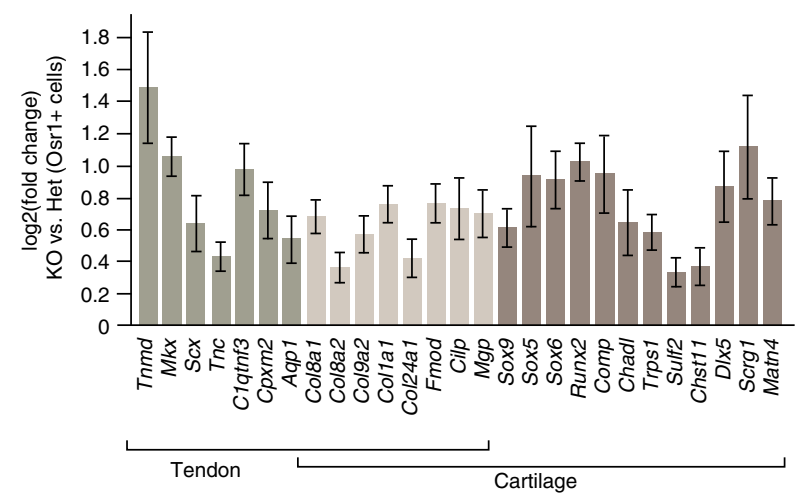

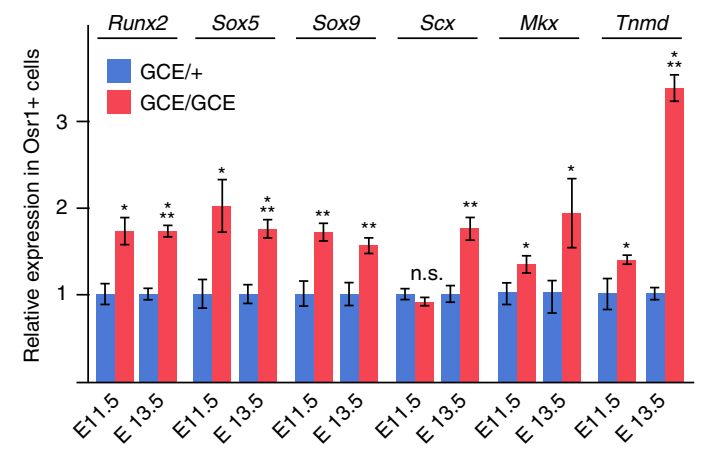

f
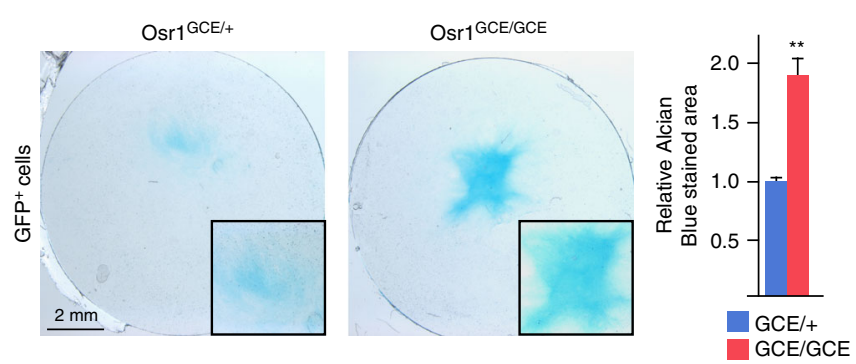

Fig. 6 Osr1 controls ECM gene expression in a bimodal way and is required to prevent ectopic cartilage / tendon gene expression. a Volcano plot depiction of transcriptome analysis of FACS-sorted Osr1 ${ }^{+}$cells from limbs of E13.5 Osr1 ${ }^{G C E /+}$ or Osr1 ${ }^{G C E} / G C E$ embryos shows differentially expressed (DE) genes between Osr GCE/+ $^{\mathrm{G}}$ and Osr7 ${ }^{\text {GCE/GCE }}$ limb cells. 511 DE genes were identified with a false discovery rate of 0,05 that showed a log2 fold change over 1,2 or below 0,8 and a Benjamini-Hochberg adjusted $p$-value (padj) <0,1. b GO analysis of all DE genes for "cellular component" showed enrichment for the indicated terms. c Heatmap depiction of all genes belonging to the term "extracellular matrix" (ECM). Selected ECM genes are indicated. $\mathbf{d}$ Bar graph plot for genes selected from all DE genes for their cartilage and/or tendon- specific expression pattern in embryo; note that all cartilage/tendon genes are upregulated in Osr1 mutants. e Confirmation of upregulation of Runx2, Sox5 and Sox9 (cartilage genes) and Scx, Mkx and Tnmd (tendon genes) in E11.5 and E13.5 Osr1 deficient cells by RT-qPCR $(n=4)$. $\mathbf{f}$ Chondrogenic culture of Osr1 ${ }^{\mathrm{GCE} /+}$ and Osr1 $\mathrm{GCE}^{\mathrm{GCE}}$ cells. Chondrogenic matrix is stained with Alcian blue, histomorphometric quantification is shown on the right. $(n=3)$. Error bars represent log2 fold change standard error (ifCSE) estimated by DESeq2 in $\mathbf{d}$ and s.e.m. in e, f. T-test: ${ }^{\star}=p<0.05 ;{ }^{\star \star}=p<0.01 ;{ }^{\star \star \star}=p<0.001$. N-numbers indicate biological replicates, i.e. samples from different specimen

development" and "cartilage development" (Supplementary Fig. 9b). Therefore, we systematically mined the DE genes for genes connected to the GO term "cartilage development" and for tendon genes based on the list identified by Havis et al. ${ }^{30}$. All identified tendon and cartilage genes were upregulated in E13.5 Osr1-KO cells compared to Osr1 heterozygous cells (Fig. 6d), which was confirmed by RT-qPCR for selected genes (tendon: Scx, Tnmd, Mkx; osteo-chondrogenic: Runx2, Sox5, Sox9) (Fig. 6e). This gene deregulation was, with the exception of Scx, already detectable at E11.5 (Fig. 6e). Accordingly, Osr1 deficient cells (Osr1 $\mathrm{GCE} / \mathrm{GCE})$ showed a higher chondrogenic capacity than Osr1 ${ }^{\mathrm{GCE} /+}$ cells in vitro (Fig. $\left.6 \mathrm{f}\right)$. These data are consistent with the presence of ectopic cartilage differentiation in synovial joints in Osr1 and Osr2 double mutants ${ }^{31}$, a requirement for Osr1 in preventing Sox9 expression and ectopic cartilage formation in the neural crest ${ }^{32}$ and the ability of Osr1 to repress tendon and cartilage differentiation in chick limb mesenchymal cells ${ }^{23}$. We note that we also observed signs of ectopic tendon differentiation in Osr1 mutants specifically between the myotendinous junctions of the Teres major and Triceps brachii lateralis muscles (Supplementary Fig. 10a). Overall, $S c x$ showed apparently increased and less confined expression in E13.5 Osr1 ${ }^{\mathrm{GCE} / \mathrm{GCE}}$ limbs compared to control limbs (Supplementary Fig. 10b).
In contrast to the upregulated cartilage/tendon ECM genes, ECM genes that were downregulated in Osrl deficient cells were expressed predominantly in irregular CT and/or MCT (based on Eurexpress data). These ECM genes encoded e.g. for collagens associated to MCT, such as COL6 (Fig. 6c, Fig. 7a). COL6, typically consisting of COL6A1, COL6A2 and COL6A3 chains, is an indispensable component of the muscular ECM mutated in human muscular dystrophies ${ }^{33}$. Furthermore COL6 has a central role in ECM assembly, since it bridges fibrillary collagens, matrix components and cell adhesion molecules ${ }^{33}$. Other CT ECM components were downregulated in Osr1 mutant cells (Fig. 6c, Fig. 7a), including members of the small leucine-rich proteoglycan (SLRP) family such as Lumican (Lum) and Decorin (Dec) that play a role in ECM assembly and cell-matrix interaction ${ }^{34}$, or the basement membrane component Nidogen 2 (Nid2). The downregulation of selected ECM genes (Col3a1, Col5a3, Colba1, Col6a2, Col6a3, Dcn, Lum, Nid2) was confirmed by RT-qPCR (Fig. 7b). Immunolabelling for pan-COL6 revealed a strong reduction of COL6 abundance in E13.5 Osr1 ${ }^{G C E / G C E}$ limbs as compared to wildtype (Fig. 7c).

We then tested which ECM genes may be direct targets of Osr1 via Chromatin immunoprecipitation (ChIP). For this purpose freshly isolated MEFs from E13.5 C57Bl6 limbs were stably transduced with lentiviral particles expressing mouse Osr1 fused 
a

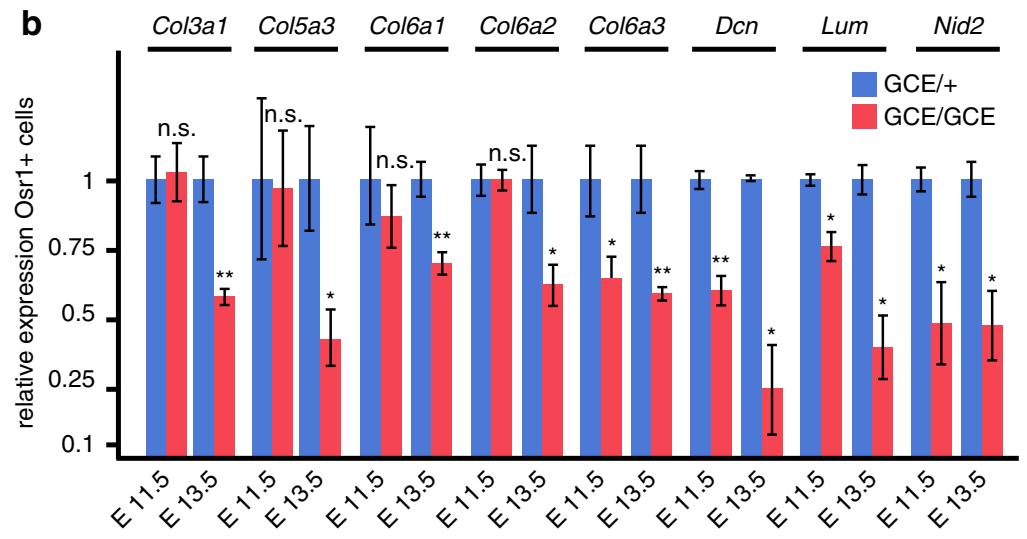

C
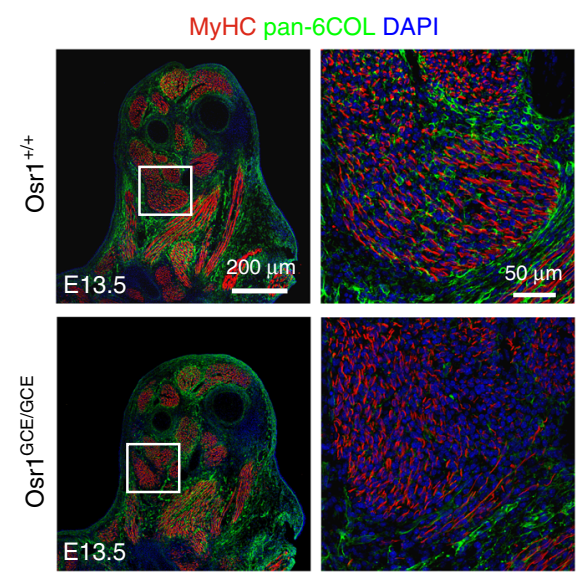

$\mathbf{f}$
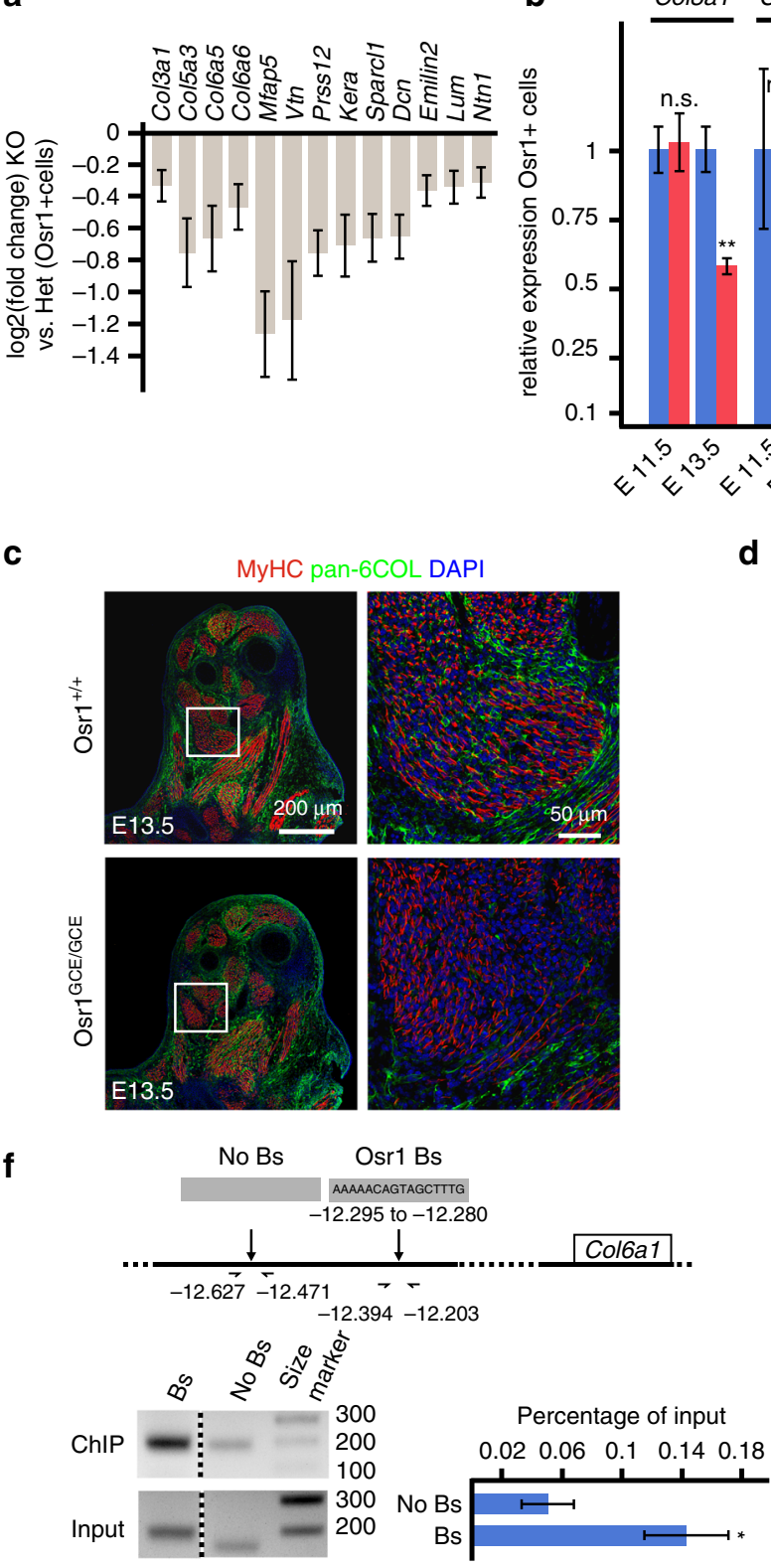

d

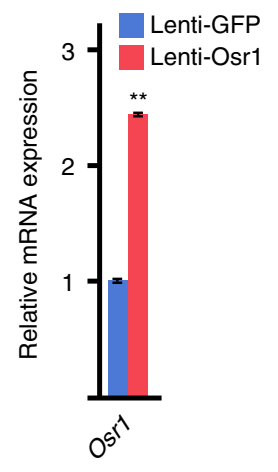

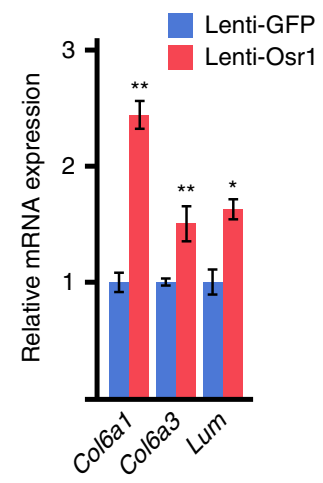
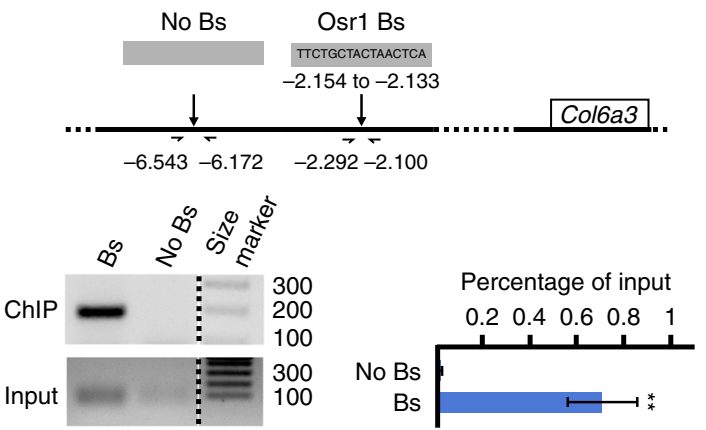

Fig. 7 Osr1 is required for muscle connective tissue ECM gene expression. a Bar graph plot of genes selected from all DE genes by their expression associated with muscle connective tissue; most of the genes belong to the downregulated cluster in (Fig. 6c). b Confirmation of downregulation of selected MCT-ECM genes in E11.5 and E13.5 Osr1 deficient cells by RT-qPCR $(n=4)$. c Immunolabelling for MyHC and COL6 shows reduced abundance of COL6 in Osr1 mutants. d Transduction of E13.5 MEFs with lentiviral particles causes mild overexpression of Osr1. e Lentiviral overexpression of Osr1 causes upregulation of Col6a1, Col6a3 and Lum genes. $\mathbf{f}$ Chromatin immunoprecipitation of putative Osr1 binding sites at the Col6a1 and Col6a3 loci. Above: schematic representation of the loci; positions of Osr1 binding sites and PCR primers relative to exon 1 of the Col6a1 and Col6a3 genes are indicated. Below: representative gel pictures of ChIP vs. input are shown left, confirmation of binding site pulldown via RT-qPCR $(n=3)$ are shown right. Bs: putative binding site, No Bs: control region. Size marker: 100 base pair ladder; band sizes are indicated in base pairs. Error bars represent log2 fold change standard error (ifcSE) estimated by DESeq2 in a and s.e.m. in (b, d, e, f). T-test: ${ }^{\star}=p<0.05 ;{ }^{\star \star}=p<0.01 ;{ }^{\star \star \star}=p<0.001$. N-numbers indicate biological replicates, i.e. samples from different specimen in $\mathbf{b}$ or independent assays in $\mathbf{d}, \mathbf{e}, \mathbf{f}$

at the $3^{\prime}$ end to a tripleFLAG tag under control of the low-active Ubiquitin $\mathrm{C}$ (UbC) promoter. This yielded mild overexpression (approximately twofold) of Osr1-tripleFLAG mRNA (Fig. 7d), which was chosen to avoid overexpression artefacts. Mild overexpression of Osr1 in MEFs was sufficient to increase the expression of Col6a1, Col6a3 and Lum mRNAs (Fig. 7e). For ChIP, upstream regions of Col6a1, Col6a3 and Lum were screened for the presence of Osr1 consensus binding sites ${ }^{35}, 36$ in the UCSC Genome Browser ${ }^{37}$. Two putative binding sites were found upstream of Col6a1, Col6a1 or Lum, respectively. ChIP yielded significant enrichment for one binding site at each the Col6a1 and the Col6a3 loci in comparison to flanking control regions without consensus binding sites (Fig. 7e, f; primer sequences for putative binding sites and controls are provided in Supplementary Table 7). These data support a direct regulation of Col6a1 and Col6a3 by Osr1. Taken together, our data support a role for Osr1 in promoting the expression of MCT-specific ECM components, while inhibiting tendon and cartilage ECM and transcription factor genes. Given that $\mathrm{Osr}^{+}$cells display high fibrogenic and adipogenic potential, we conclude that Osr1 is a 


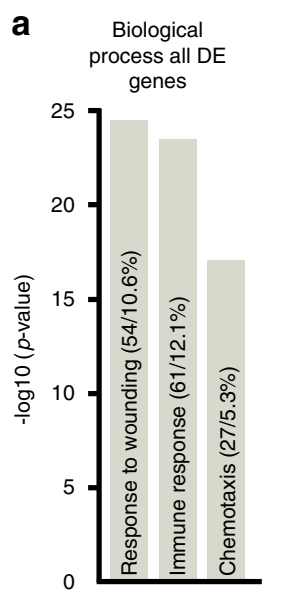

b KEGG pathways downregulated genes

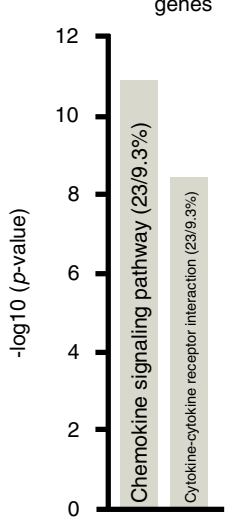

e

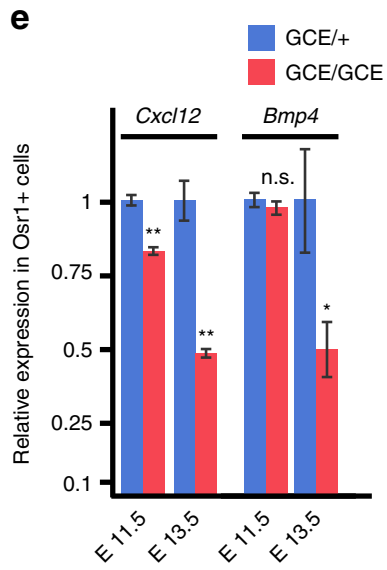

C

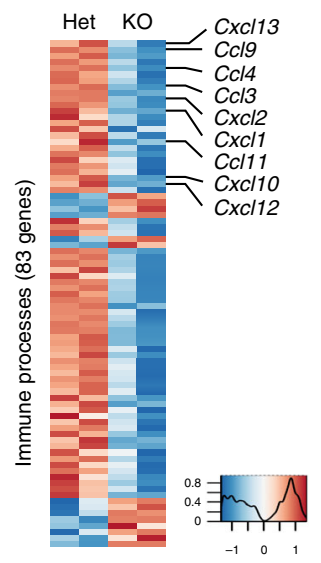

d

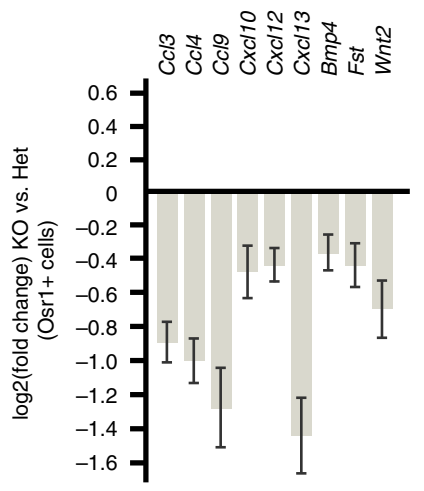

f

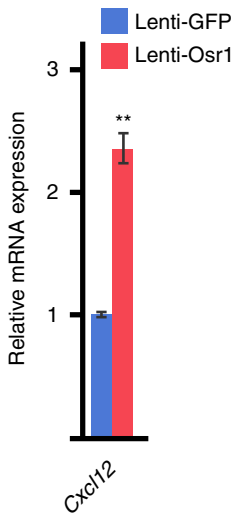

g
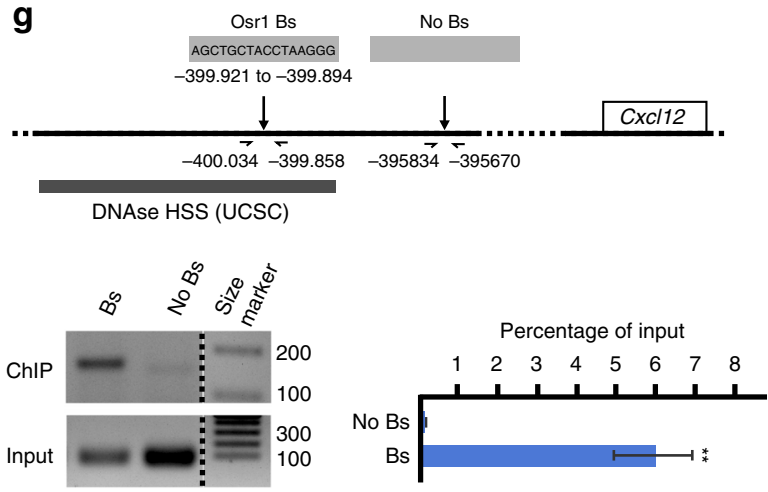

Fig. 8 Osr1 cells are a source or growth factor signalling and Osr1 directly controls Cxcl12 expression. a Gene ontology (GO) analysis for "biological process" using all deregulated (DE) genes (Osr1 ${ }^{G C E /+}$ vs. Osr $7^{G C E / G C E}$ cells) showed significant enrichment for the indicated terms. b KEGG pathway analysis of downregulated genes. c Heatmap depiction of all non-redundant DE genes contained in the GO terms shown in c collectively termed "immune processes". Several genes for signalling molecules from chemokine families appear downregulated in Osr ${ }^{G C E / G C E}$ limb cells. d Deregulation of secreted signalling molecules selected from all DE genes for their previously demonstrated role in myogenesis. e Confirmation of downregulation of Cxcl12 and Bmp4 in Osr1deficient cells isolated at E11.5 and E13.5 by RT-qPCR $(n=5)$. $\mathbf{f}$ Upregulation of Cxcl12 upon lentiviral Osr1 overexpression. $\mathbf{g}$ Chromatin immunoprecipitation (ChIP) for a putative Cxcl12 enhancer. Representative gel pictures of ChIP vs. input are shown below schematic representation of the locus, confirmation of binding site pulldown via RT-qPCR $(n=3)$ shown right. Bs: putative binding site, No Bs: control region. DNAse HSS: DNAsel hypersensitive regions according to UCSC. Size marker: 100 base pair ladder; band sizes are indicated in base pairs. Error bars represent log2 fold change standard error (ifCSE) estimated by DESeq2 in $\mathbf{d}$ and s.e.m. in $\mathbf{e}, \mathbf{f}, \mathbf{g}$. T-test: ${ }^{\star}=p<0.05 ;{ }^{\star \star}=p<0.01$. N-numbers indicate biological replicates, i.e. samples from different specimen in $\mathbf{e}$ or independent assays in $\mathbf{f}, \mathbf{g}$

key transcription factor that maintains embryonic Osr $1^{+} \mathrm{FAP}$ cell identity. Loss of Osr1 in turn leads to a shift in embryonic FAP transcriptional activity from an ECM characteristic for MCT to cartilage/tendon ECM.

Osri $^{+}$cells are a source of secreted signalling molecules. In addition to MCT-ECM components, we searched for DE genes encoding secreted signalling molecules in Osr1-deficient cells. GO analysis of all DE genes or only downregulated genes for "biological processes" showed similar enrichment for the terms "response to wounding", "immune response" and "chemotaxis" (Fig. 8a, Supplementary Fig. 9c). Consistently, KEGG analysis of all DE genes or only downregulated genes showed enrichment for "chemokine signalling" and associated pathways (Fig. 8b, Supplementary Fig. 9a). Consistently, genes associated with these terms, containing many members of chemokine family, were mostly downregulated in Osr1 mutants (Fig. 8c), as were genes encoding several other myogenesis-related signalling factors such as Bmp4 (Fig. 8d). The decrease in expression levels of Cxcl12 and Bmp4 mRNAs was confirmed by RT-qPCR in $\mathrm{Osr}^{+}$cells (Fig. 8e). Overexpression of Osr1 induced an increase in Cxcl12 mRNA in MEFs (Fig. 8f). The Cxcl12 locus showed one consensus Osr1 binding site approx. $18 \mathrm{~kb}$ upstream and two distant upstream consensus binding sites within DNAseI hypersensitive regions (UCSC) in the gene desert $5^{\prime}$ of Cxcl12. A distant $5^{\prime}$ element located approx. $400 \mathrm{~kb}$ upstream of $\mathrm{Cxcl} 12$ was bound by Osr1 (Fig. 8g; primer sequences are provided in Supplementary Table 7). Together this indicated direct regulation of Cxcl12 by Osr1 via binding to this putative enhancer element. 
Osr $^{+}$FAPs provide a myogenic niche in developing limbs. The transcriptional aberrations in Osr1 deficient cells were in part observed as soon as E11.5 concomitant with the reduced myogenic cell pool. A significant downregulation at E11.5 was found for the MCT-ECM genes Col6a3, Lum, Dcn and Nid2. In contrast, Col3a1, Col5a3, Col6a1 and Col6a2 showed no significant difference in $\mathrm{Osrl}^{+}$cells isolated at E11.5 (Fig. 6b). However, COL6 expression was severely decreased in E11.5 Osr1 ${ }^{G C E / G C E}$ limb muscles (Fig. 9a) indicating that the decrease of Col6a3 mRNAs was sufficient to affect COL6 expression in line with previous in vitro and in vivo observations ${ }^{38,}{ }^{39}$. The COL6 decrease was accompanied by a decrease of Fibronectin (FN) a

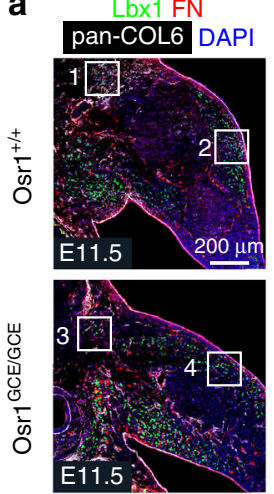

C
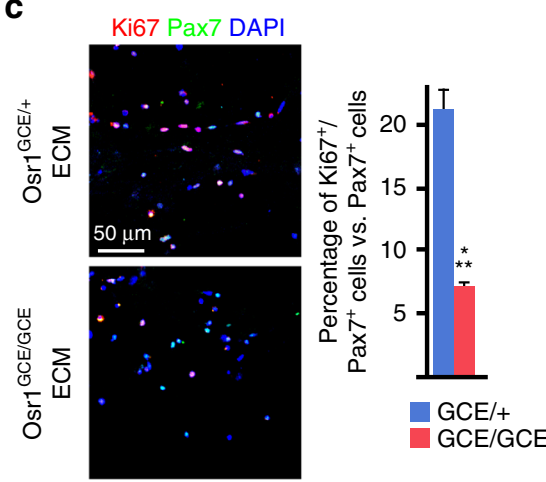

$\mathbf{f}$

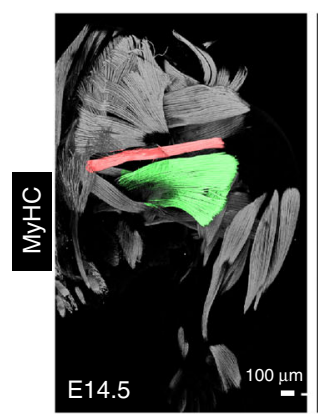

Biceps femoris anterior head Biceps femoris accessory / posterior head
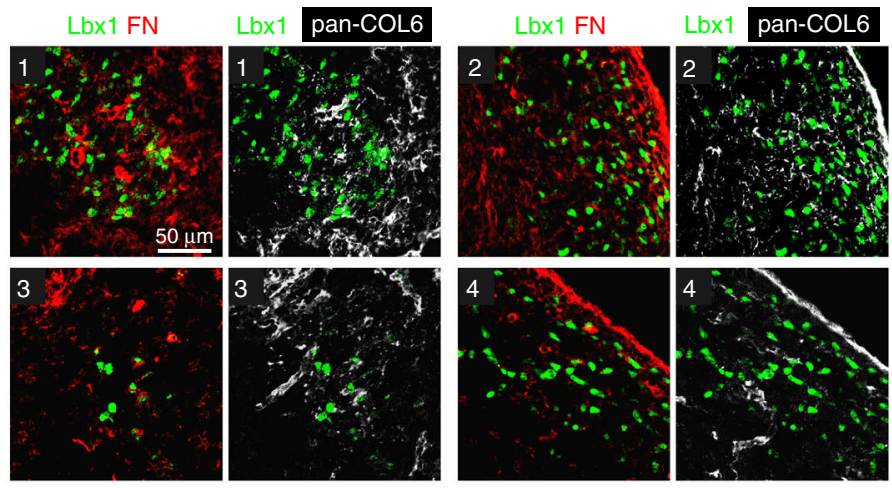

d
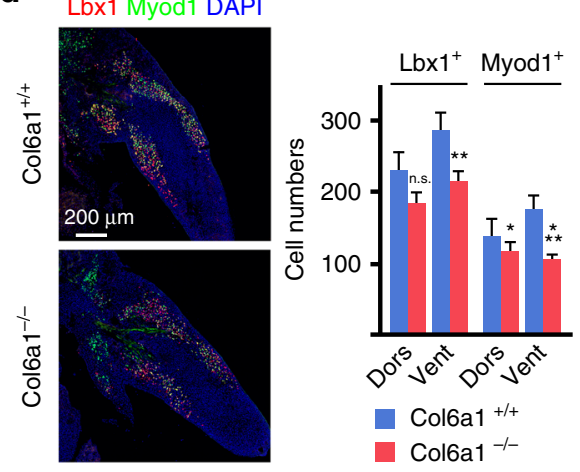

g
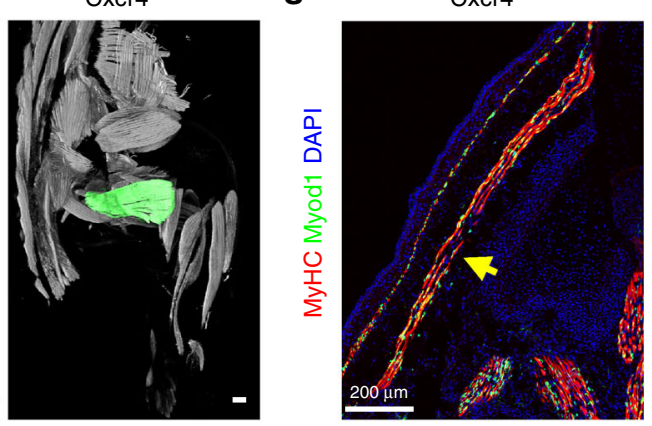

Biceps femoris anterior head b

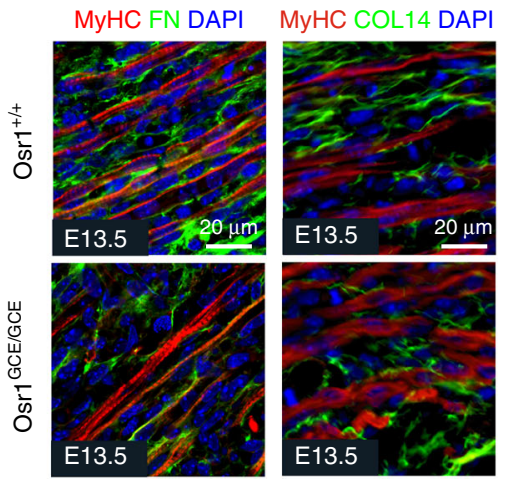

e

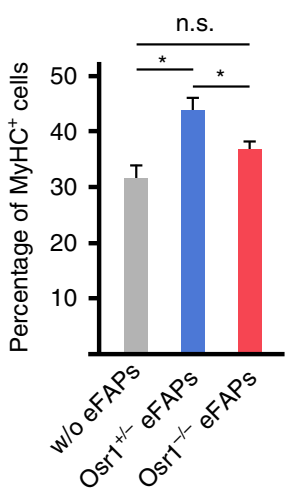

$\mathrm{Cxcr}^{+/+}$

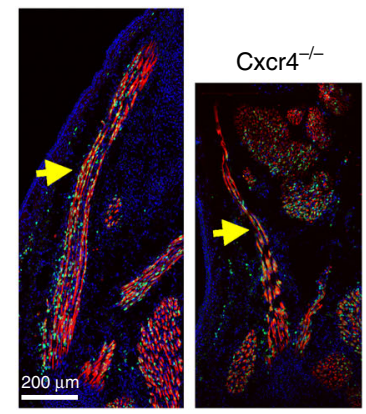

Biceps femoris accessory head h

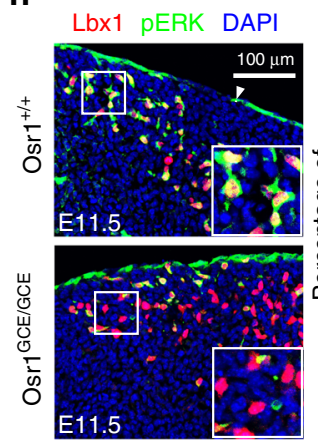

i$$
\text { ( }
$$

Lbx1 CyclinD1 DAPI

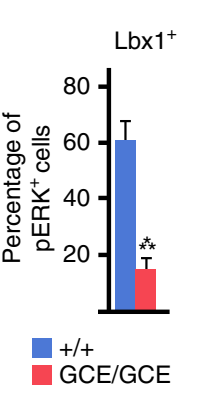

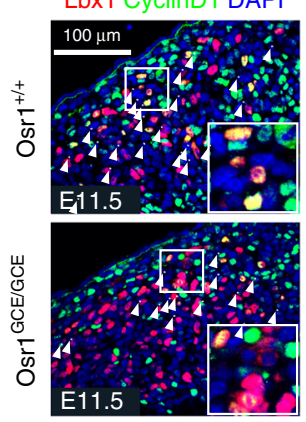

$\mathbf{j}$

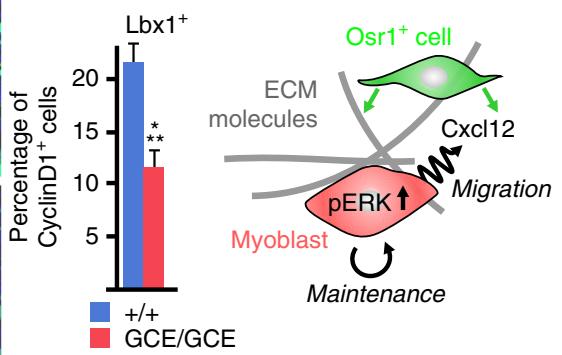

$\mathbf{k}$

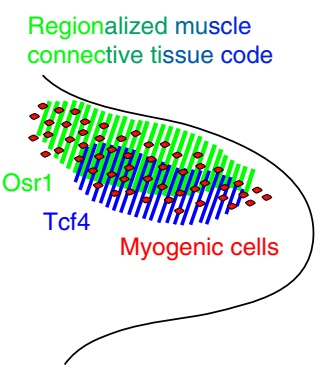


abundance (Fig. 9a), while the Fn1 gene was not deregulated at the mRNA level (log2 fold change $=0,09$ ). This is consistent with the impairment of FN deposition and organization in cultured fibroblasts with reduced or absent COL6 expression ${ }^{40}$. The reduction of FN abundance was maintained at E13.5 (Fig. 9b). Labelling for type XIV Collagen (COL14) also revealed a disruption of ECM structure (Fig. 9b). COL14 is a fibril-associated collagen with interrupted triple helices (FACIT) that is important for assembly of the fibrillary collagens and for crosslinking these to other ECM components like SLRPs such as Decorin ${ }^{41}$. This altogether confirms that the MCT-ECM is disorganized in Osr1 mutants. The ECM components FN and Vitronectin (Vtn), the latter of which was downregulated in RNA-Seq (Figs. 6c, 7a), are known to enhance proliferation of cultured myoblasts ${ }^{42,43}$. This emphasizes that a specific composition of the MCT-ECM is crucial for regulating embryonic myoblast proliferation. To analyse if Osr1 cells could influence myoblast proliferation via their ECM production, we cultured FACS-isolated Osr1 $1^{\mathrm{GCE} /+}$ and Osr1 ${ }^{\mathrm{GCE} / \mathrm{GCE}}$ cells for 10 days to produce an ECM substrate on the culture plate ${ }^{44}$. After decellularization, myogenic cells FACS isolated from new born wild type mice $\left(\mathrm{CD} 45^{-}\right.$;CD $31^{-}$; Ter119 ${ }^{-}$; $\mathrm{Scal}^{-} ; \alpha 7$-integrin $\left.{ }^{+}\right)$were seeded on the ECM substrate and tested for proliferation. ECM produced by Osr $1^{\mathrm{GCE} /+}$ cells significantly enhanced myogenic cell proliferation in comparison to cultivation on ECM produced by Osr1 ${ }^{\mathrm{GCE} / \mathrm{GCE}}$ cells. (Fig. 9c). As a model for an isolated ECM defect we analysed the number of myogenic cells in Col6a1 mutants, in which production of mature COL6 is disrupted ${ }^{45}$. Col6a1 mutants showed a comparable decrease in myogenic cell number as Osr1 mutants in E11.5 limbs (Fig. 9d). Together this suggests that $\mathrm{Osr}^{+}$cells promote the expansion of the myogenic progenitor pool via the ECM, with COL6 as a major constituent and direct Osr1 target.

It was shown before that neonatal limb MCT fibroblasts supported myogenesis in transwell assays ${ }^{12}$ indicating that MCT cells exert at least part of their function via the production of secreted signalling molecules. We discovered several secreted signalling factors downregulated in Osr1-deficient embryonic FAPs, amongst them Cxcl12 as direct Osr1 target. Cxcl12 and its receptor Cxcr4 are known to be involved in muscle cell proliferation in vitro ${ }^{46}, 47$, and both $\mathrm{Cxcl} 12$ and $\mathrm{Cxcr} 4$ are involved in mouse limb myogenesis in vivo ${ }^{48,49}$. We tested if $\mathrm{Osr}^{+}$cells have the ability to enhance myogenesis via diffusible components using transwell assays. FACS-isolated E13.5 Osr1 ${ }^{\mathrm{GCE} /+}$ or Osr1 ${ }^{\mathrm{GCE} / \mathrm{GCE}}$ cells were seeded into transwell inserts, myoblasts FACS isolated from new born wild type mice were seeded into cultivation wells. Osr1 $1^{\mathrm{GCE} /+}$ cells significantly supported myogenesis as compared to cultivation with Osr1 ${ }^{\mathrm{GCE} /}$ GCE cells or cultivation without any cells (Fig. 9e). To further elucidate to which extent the downregulation of the direct Osr1 target Cxcl12 may be involved in the Osr1 KO phenotype we analysed mouse mutants for the Cxcl12 receptor Cxcr4 at E14.5 for muscle patterning defects via whole limb immunolabelling. We observed defects that partly overlap with those of Osr1 mutants, such as reduction on muscle size in the Biceps femoris muscles (Fig. 9f, g). For the Biceps femoris anterior head the phenotype of Cxcr4 mutants was exacerbated compared to Osr 1 mutants (Fig. 9g). In C2C12 myogenic cells, the Cxcl12/Cxcr4 axis signals via the MAPK/ERK pathway ${ }^{47}$. The ERK pathway is also one major downstream component of integrin/focal adhesion signalling triggered by cell-ECM interaction in myogenesis ${ }^{50}$. ERK phosphorylation was significantly decreased in $\mathrm{Lbxl}^{+}$ myogenic progenitors in Osr1 mutants (Fig. 7h). A downstream target of ERK in this context is Cyclin D1 $1^{51,52}$, which was less abundant in $\mathrm{Lbx}^{+}$nuclei in $\mathrm{Os} r 1$ mutants compared to wildtype (Fig. 7i). Altogether, we propose that Osr1 ${ }^{+}$embryonal FAPs positively regulate myoblast proliferation and survival via a combination of ECM and paracrine signalling.

\section{Discussion}

Correct number and distribution of myogenic progenitors emanating from the initial muscle anlagen is essential for embryonic muscle patterning, a process controlled by local MCT cells ${ }^{8-10}$. During this process the MCT cells are thought to create a promyogenic environment ${ }^{13}$, such as a myogenic niche, that is so far not well characterized. We show here that $\mathrm{Osr}^{+}$cells define a population of embryonic FAPs as a subpopulation of MCT. We demonstrate in vitro that $\mathrm{Osr}^{+}$cells are capable of creating such a niche environment and that Osr1 is essential for their promyogenic capacity in vitro and in vivo.

Our data suggest that Osr1 specifies MCT cell fate and drives a transcriptional program of MCT-ECM genes in these cells. Thereby Osr1 directly controls the expression of Col6a1 and Col6a3, encoding two essential subunits of COL6. The ECM produced by $\mathrm{Osr}^{+}$cells provides an environment for myogenic cells that promotes their proliferation and survival. Based on the transcriptome data, we propose that Osr1 drives the transcription of ECM genes, directly or indirectly, that includes not only a subset of ECM components such as Collagens, but also components essential for collagenous matrix assembly as Lumican, Matrillin, Decorin and Fibromodulin ${ }^{53}$. Hence the combined defect seen in Osr1 mutants should exacerbate effects seen in mouse models for individual ECM components such as Col6a1 null mice. Indeed, the number of myogenic cells displays a more pronounced decrease in $\mathrm{Osr} 1^{\mathrm{GCE} / \mathrm{GCE}}$ than in Col6a1 $1^{-/-}$embryos at E11.5. In addition, no obvious muscle patterning phenotype was observed in 3D reconstructions of Col6 $\mathrm{al}^{-1-}$ limbs at E14.5 (Supplementary Fig. 11), indicating that myogenic cell numbers may be caught up later in Col6a1 $1^{-1-}$ embryos. This is not the case in Osr1 mutants, where the number and proliferation rate of

Fig. 9 Osr1-deficiency impairs the myogenic niche in developing limbs. a Decreased abundance of COL6 and FN (Fibronectin) in proximal (inserts 1 and 3) and dorsal (inserts 2 and 4) muscle primordia of Osr1-deficient E11.5 limbs. Boxed regions are shown in the numbered panels to the right and are magnifications of the area. b Reduced abundance of interstitial FN and disarrangement of COL14 in E13.5 Osr1 ${ }^{\text {GCE/GCE }}$ limb muscles as compared to wildtype littermate controls. c Extracellular matrix (ECM) produced by Osr1 ${ }^{\mathrm{GCE} /+}$ cells, but not ECM produced by Osr1 ${ }^{\mathrm{GCE} / \mathrm{GCE}}$ cells supports myoblast proliferation $(n=3)$. d E11.5 Col6a1 $1^{-/-}$embryos show a decrease in myogenic progenitor numbers $(n=3)$. e Transwell assay shows a beneficial effect of E13.5 Osr1 ${ }^{\mathrm{GCE} /+}$ embryonic FAPs (eFAPs) but not Osr1 ${ }^{\mathrm{GCE} / \mathrm{GCE}}$ eFAPs on myogenesis. Transwell culture without eFAPs was used as control ( $n=3$ ). $\mathbf{f} C x \mathrm{Cr} 4$ $-{ }^{-}$embryos show muscle defects overlapping with Osr1 ${ }^{\mathrm{GCE} / \mathrm{GCE}}$ embryos. $\mathbf{g}$ Sections of $\mathrm{CxCr} 4^{+/+}$and $\mathrm{CxCr} 4^{-/-}$embryos show almost complete reduction of the biceps femoris anterior head and hypoplasia of the biceps femoris accessory head. $\mathbf{h}$ Decreased phosphorylated ERK (pERK) and (i) CyclinD1 in myogenic Lbx1 $1^{+}$cells in E11.5 Osr1 mutants $(n=3)$. j Schematic model of Osr1 ${ }^{+}$cell function. Osr1 ${ }^{+}$cells (green) produce chemokines as Cxcl12 and a specific extracellular matrix (ECM) supporting myoblast proliferation and survival involving pERK signaling. Cxcl12 in addition likely provides local migratory cues ensuring correct spatial distribution of myoblasts as a prerequisite for muscle patterning. $\mathbf{k}$ Schematic model of limb muscle connective tissue compartmentalization. Specific transcription factors (Osr1 and Tcf4 are shown as examples) are expressed regionally in the limb bud with areas of overlap creating a regionalized code that likely determines the composition of the local niche. Error bars represent s.e.m. T-test: ${ }^{\star}=p<0.05 ;{ }^{\star \star}=p<0.01$; ${ }^{\star \star \star}=p<0.001$. N-numbers indicate biological replicates, i.e. samples from different specimen in $\mathbf{d}, \mathbf{h}, \mathbf{i}$ or independent assays in $\mathbf{c}, \mathbf{e}$ 
myogenic cells are still decreased at E13.5 (Supplementary Fig. 8e, f) and patterning defects are already visible at this stage (Fig. 5d).

In addition to providing a beneficial ECM environment, we show that $\mathrm{Osr1}^{+}$embryonic FAPs express signalling molecules such as $\mathrm{Cxcl} 12$ and Bmp4 known to be involved in myogenesis. Both factors can promote myoblast proliferation $46,47,54,55$. Cxcl12/Cxcr4 signalling was also involved in myoblast survival ${ }^{48}$ thus defective signalling likely contributes to the reduction of the myogenic pool on top of the ECM defects described above. Intriguingly, both ECM / focal adhesion signalling as well as Cxcl12/Cxcr4 signalling can feed into the ERK pathway ${ }^{47,50,}$ which we show is strongly impaired in limb myoblasts of Osr $1^{-1-}$ embryos. Moreover, Cxcl12 promotes myoblast migration in vitro and in vivo ${ }^{48,56}$ and deficiency of Cxcr4 impairs myoblast migration in vivo ${ }^{48}$. A significant early migration phenotype was however only observed in compound mutants for Cxcr4 and $G a b 1$, an adaptor and signal mediator protein for c-met ${ }^{48}$. An overt muscle patterning phenotype was not demonstrated in Cxcr4 mutant mice, however they show a mild reduction of myogenic cell numbers in the limb with increased apoptosis and altered distribution of myoblasts ${ }^{48}$. We show here that Cxcr4 mutants show overlapping muscle patterning defects as Osr1 mutants. In case of the Biceps femoris anterior head Cxcr4 mutants show increased severity compared to Osr1 mutants, which could be expected from a full loss of a receptor as compared to a partial loss of its ligand. We propose that Cxcl12 produced by $\mathrm{Osr}^{+}$cells may provide local migration cues for myogenic cells to reach their correct target areas in the phase of muscle patterning. A failure of this local mechanism may explain the absence of myogenic cells in areas normally populated by myoblasts (Fig. 5b). We therefore conclude that embryonic Osr1 ${ }^{+}$ FAPs are a vital part of a developmental myogenic niche consisting of a muscle-specific ECM and a favourable signalling environment. Both components are linked, since composition of the ECM strongly influences signalling by secreted molecules ${ }^{57}$ and both mechanisms can feed into overlapping intracellular signalling pathways that together maintain the myogenic cell pool and ensure its correct spatial distribution via directed local migration (Fig. 9j).

Several transcription factors that are expressed in limb connective tissue were shown to influence muscle patterning, namely Tcf4, Tbx4, Tbx5, Hoxa11 and Hoxd11 12, 58, 59, although their modes of action are mostly unclear. None of these genes were obviously deregulated in Osr1-deficient cells or in Osr1-deficient limbs (Supplementary Fig. 9d, f) suggesting that Osr1 acts in a different genetic pathway or downstream of these transcription factors.

To date, Tcf4 is the most commonly accepted marker for MCT fibroblasts. We show that during embryonic myogenesis, Tcf4 exhibits a highly regionalized expression, which is mutually exclusive with Osr1 in many places and overlapping in others (Fig. 2). This implies that neither Tcf4 nor Osr1 are universal markers for limb MCT. However, the level of coexpression of Osr1 and Tcf4 in MCT cells is increased during development, and $\mathrm{Tcf}^{+}$cells can arise from Osr1 ${ }^{+}$progenitors. This is in accordance with the uniform expression of Tcf4 in MCT of all limb muscles in neonatal mice as reported by Mathew et al. ${ }^{12}$. This suggests that embryonic MCT has a regionalized character where subpopulations are identifiable by the expression of specific transcription factors. During development each positional value in the limb may be characterized by a combination of instructive transcription factors. This concept suggests a toolbox of transcription factors as easily adaptable determinants of the specific local myogenic niche character, which might control the shaping of individual muscles (Fig. 9k). After the initial patterning phase this regional MCT subdivision seems to dissolve since at birth most MCT cells appear to have assumed Tcf4 expression ${ }^{12}$, while Osrl expression is fading.

We show here that the embryonic FAPs are lineage progenitors of adult muscle interstitial FAPs. Osr $1^{+}$cells uniquely contribute to FAPs and not to other mononuclear cell populations identifiable by the FACS protocol we used ${ }^{20}$. The overall contribution of developmental Osr1 ${ }^{+}$cells to adult limb FAPs detected by our protocol was moderate. This is however not surprising given that for cell isolation all limb muscles were used, while Osr1 is only expressed in a subset of muscles during development. Consequently, when counting the contribution of Osr $1^{+}$progenitors to FAPs on sections, a considerably higher contribution rate was found in individual muscles correlating with developmental Osr1 expression. We chose a protocol of timely limited administration of moderate TAM doses over either a time-extended administration of high TAM doses or constitutive Cre strategies, since our strategy provides high specificity, however at the expense of efficacy. Together, our data show that adult FAPs derive in part from Osr $1^{+}$progenitors, but this is unlikely the only developmental source. Of note we report here quantitative data showing that a majority of adult FAPs express Tcf4 (Fig. 4d) in agreement with observations made by Murphy et al. ${ }^{14}$ suggesting that $\mathrm{Tcf} 4{ }^{+}$ muscle connective tissue fibroblasts and FAPs are in fact largely, however not completely overlapping populations in the adult muscle interstitium, as proposed previously ${ }^{14,19}$. During muscle regeneration, FAPs are thought to be vitally involved in creating a specific, yet mostly undefined, niche for satellite cells $14,17,19,20,60$. Future studies will determine whether adult FAPs employ similar mechanisms for regenerative myogenesis as their developmental predecessors.

\section{Methods}

Animals. Mice were maintained in an enclosed, pathogen-free facility, and experiments were performed in accordance with European Union regulations and under permission from the Landesamt für Gesundheit und Soziales (LaGeSo) Berlin, Germany (Permission numbers ZH120, G0346/13, G0240/11). Mouse lines used: Pax3 $3^{\text {GFP61 }}$, Osr1 ${ }^{\text {GCE25 }}$, R26R $^{\text {mTmG62 }}$, R26R $^{\text {LacZ63 }},{\text { Col } 6 a 1^{+/-45}}$ and Cxcr4 ${ }^{+-64}$

Cell proliferation analysis. Bromodeoxyuridine (BrdU, Roche) was administered intraperitoneally to pregnant females $\left(50 \mathrm{mg} \mathrm{kg}^{-1}\right)$ at the desired stage. Embryos were collected $1 \mathrm{~h}$ after BrdU administration for assessing proliferation rates. After immunolabelling (see below) $\mathrm{Lbxl}^{+}, \mathrm{Pax}^{+}$or Myod $1^{+}$nuclei positive or negative for BrdU, respectively, were counted in a defined area. To establish the proliferation rate double positive cells were set in relation to the total cell number positive for the respective marker.

Tamoxifen administration and Osr1 cell lineage tracing. Tamoxifen (Sigma Aldrich) was dissolved in a 1:10 ethanol/sunflower oil mixture. For embryonic lineage tracing, pregnant $R 26 R^{m T m G / m T m G}$ females that had been bred to Osr $1^{G C E /}$ ${ }^{+}$males were injected with $150 \mu \mathrm{l}$ of a $20 \mathrm{mg} \mathrm{mL}^{-1}$ Tamoxifen stock. Tissues were collected at E18.5. Upon CreERt2 activation, the mTmG allele is converted as to switch cells from membrane tomato (mT) expression to membrane eGFP (mG) expression. Importantly, $\mathrm{mG}$ expression driven by the CMV enhancer/beta-actin core promoter cassette can be visualized by direct microscopy without antibody labelling. This, and the membrane localization, differentiates $\mathrm{mG}$ expressed from the $R 26 R^{m T m G}$ allele from the cytoplasmic eGFP expressed from the Osr $1^{G C E}$ allele, which was not detectable without prior immunolabelling for GFP under the experimental conditions used here.

For postnatal lineage tracing, new born $\mathrm{Osr} 1^{G C E /+} ; R_{2} 26 R^{\mathrm{LacZ} /+}$ or Osr1 ${ }^{\mathrm{GCE} /+}$; $\mathrm{R} 26 \mathrm{R}^{\mathrm{mTmG} /+}$ pups were injected subcutaneously into the neck fold with $25 \mu \mathrm{l}$ of a $3 \mathrm{mg} \mathrm{ml}^{-1}$ Tamoxifen stock. Adult tissue was collected at 12 weeks of age. Expression of beta-Galactosidase (bGal) from the $R 26 R^{\text {LacZ }}$ allele was detected by immunolabelling (see below).

Tissue preparation. For immunolabelling, embryonic tissues were fixed in $4 \%$ PFA for $2 \mathrm{~h}$ at RT and treated with successive 15 and $30 \%$ (w/v) sucrose (Roth) solutions before O.C.T. (Sakura) cryo-embedding in a chilled ethanol bath. Embryonic tissue was sectioned at $12 \mu \mathrm{m}$ thickness and stored at $-80^{\circ} \mathrm{C}$ until use. Adult muscle tissues were directly embedded in gum Tragacanth $6 \%(\mathrm{w} / \mathrm{v})($ SigmaAldrich) and flash frozen using a chilled $\left(-160^{\circ} \mathrm{C}\right)$ isopentane (Carl Roth) bath. Adult tissues were cut at $7 \mu \mathrm{m}$ thickness and fixed in $4 \%$ PFA for $5 \mathrm{~min}$ at room temperature. For section in situ hybridization tissue was fixed in $4 \%$ 
paraformaldehyde dissolved in diethylpyrocarbonate (DEPC)-treated PBS for $2 \mathrm{~h}$ at room temperature. Tissue was sectioned at $10 \mu \mathrm{m}$ thickness and stored at $-80^{\circ} \mathrm{C}$ until use. For whole-mount in situ hybridization embryos were fixed in $4 \% \mathrm{PFA} /$ DEPC-PBS at $4{ }^{\circ} \mathrm{C}$ overnight. After fixation embryos were washed with DEPC-PBS and $0,1 \%$ Tween-20 (PBST) for $30 \mathrm{~min}$ on ice. Embryos were dehydrated in Methanol and stored at $-20^{\circ} \mathrm{C}$ until use.

Immunolabelling. Permeabilization of sections was performed in $0.3 \%(\mathrm{v} / \mathrm{v})$ Triton X-100 (Sigma Aldrich) in phosphate buffer (PBS) for $10 \mathrm{~min}$. Sections from adult tissues were blocked with $5 \%(\mathrm{w} / \mathrm{v})$ bovine serum albumin (Sigma Aldrich) in PBS. Antigen retrieval was performed where necessary: for Pax7 immunostaining, sections were treated for $6 \mathrm{~min}$ in $-20^{\circ} \mathrm{C}$ chilled methanol and subsequently washed in PBS. Further epitope retrieval was performed by a treatment with $1 \mathrm{mM}$ Ethylendiaminetetraacetic acid (Roth) at $95^{\circ} \mathrm{C}$ for $10 \mathrm{~min}$. For BrdU detection sections were treated using $7.5 \% 1 \mathrm{~N} \mathrm{HCL}$ at $37^{\circ} \mathrm{C}$ during $30 \mathrm{~min}$. Cleaved Caspase 3 antibody staining was preceded by an antigen retrieval consisting of a treatment with citrate buffer, $10 \mathrm{mM}$ sodium citrate (Roth) $\mathrm{pH} 6$, at $95^{\circ} \mathrm{C}$ for $10 \mathrm{~min}$. Sections were blocked with $5 \%$ horse serum, $5 \mathrm{mg} \mathrm{mL}^{-1}$ blocking reagent (Perkin Elmer) and $0.1 \%$ Triton X-100 in PBS for $1 \mathrm{~h}$ at RT. Primary antibodies were incubated at $4{ }^{\circ} \mathrm{C}$ overnight, followed by secondary antibody staining of $1 \mathrm{~h}$ at room temperature. Antibodies used for these experiments are listed in Supplementary Tables 3 and 4. Specimens were counterstained with $5 \mu \mathrm{g} \mu \mathrm{L}^{-1} 4^{\prime}, 6$-diamidino-2-phenylindole (DAPI; Invitrogen) and mounted with FluoromountG (SouthernBiotech).

For immunolabelling of cells samples were fixed using 4\% PFA for $2 \mathrm{~h}$ at room temperature. Samples were blocked and permeabilized with $5 \%$ horse serum, $5 \mathrm{mg}$ $\mathrm{mL}^{-1}$ blocking reagent (Perkin Elmer) and $0.1 \%$ Triton X-100 in PBS for $1 \mathrm{~h}$ at RT followed by primary and secondary antibody incubation as above. Cytospincollected cells were fixed with $4 \%$ PFA for $10 \mathrm{~min}$ at $4{ }^{\circ} \mathrm{C}$ and subjected to immunolabelling as above.

In situ hybridization. Digoxygenin-labelled Riboprobes for in-situ hybridization were made with the DIG RNA labelling kit (Roche: 11175033910) according to the manufacturer's instructions. Probes used in this study are listed in Supplementary Table 5 .

For section in-situ hybridization cryosections were washed three times with DEPC-PBS and treated with acetylation buffer $(0,75 \%$ triethanolamine, $0,15 \%$ hydrogen chloride and $0,2 \%$ acetic anhydride in $\mathrm{DEPC}-\mathrm{H}_{2} \mathrm{O}$ ) for $10 \mathrm{~min}$ under agitation. Acetylation buffer was washed out with DEPC-PBS. Sections were incubated for at least $2 \mathrm{~h}$ at room temperature in pre-hybridization buffer $(50 \%$ Formamide, $5 \mathrm{x}$ concentrate sodium saline citrate buffer (SSC) $\mathrm{pH} 4.5,1 \%$ SDS, $0,1 \%$ Tween-20). Riboprobes were diluted in hybridization buffer $(10 \mathrm{mM}$ Tris $\mathrm{pH}$ 7.5, $600 \mathrm{mM} \mathrm{NaCl}, 1 \mathrm{mM}$ EDTA, 0,25\% SDS, 10\% Dextran sulfate, 1x Denhardt's $200 \mu \mathrm{g} / \mathrm{ml}$ yeast tRNA and 50\% Formamide) and added to the slides. Slides were covered with a glass coverslip followed by hybridization at $65^{\circ} \mathrm{C}$ overnight in a humidified chamber. Coverslips were removed by washing in 2x SSC for $5 \mathrm{~min}$ at room temperature. Unhybridized RNA probe was removed by washing the slides twice in $2 \mathrm{x}$ SSC at $65^{\circ} \mathrm{C}$ for $30 \mathrm{~min}$ followed by two washing steps in MABT-buffer ( $100 \mathrm{mM}$ Maleic acid $\mathrm{pH} \mathrm{6,0.1 \%} \mathrm{Tween)} \mathrm{for} 30 \mathrm{~min}$ at room temperature. Slides were blocked in $500 \mu$ l blocking solution (MABT-buffer $+5 \%$ blocking reagent Roche 1109617001) for $1 \mathrm{~h}$ at room temperature in a PBS humidified chamber. Anti-DIG antibody (Roche: 11093274910) was dissolved 1:2000 in blocking solution, added to the sections and incubated overnight at room temperature. Antibody solution was washed off with MABT five times for $30 \mathrm{~min}$ at room temperature. Slides were treated twice with NTMT-buffer $(100 \mathrm{mM} \mathrm{NaCl}, 100 \mathrm{mM}$ Tris $\mathrm{pH} 9.5,50 \mathrm{mM} \mathrm{MgCl} 2$ and $0,1 \%$ Tween-20) for $10 \mathrm{~min}$ at room temperature followed by signal detection with detection solution $(5 \mu \mathrm{g} 4$-Nitro blue tetrazolium chloride (NBT) and 2.6 $\mu \mathrm{g} \mathrm{5}$-bromo-4-chloro-3-indolyl-phosphate (BCIP) dissolved in NTMT). Signal detection was performed at $37^{\circ} \mathrm{C}$ in a light protected chamber. Staining reaction was stopped by washing the slides in PBS for $5 \mathrm{~min}$. If further antibody staining was desired, sections were directly processed for immunolabelling (see above).

For whole-mount in-situ hybridization embryos were rehydrated in DEPC-PBS and bleached in $6 \%$ hydrogen peroxide in PBST for $1 \mathrm{~h}$ on ice. For permeabilization embryos were treated with $20 \mathrm{mg} / \mathrm{ml}$ proteinase $\mathrm{K}$ at room temperature for $8 \mathrm{~min}$. Embryos were washed twice in DEPC-PBST and post-fixed for $20 \mathrm{~min}$ in $4 \%$ PFA in DEPC-PBS at room temperature followed by brief washing in DEPC-PBST. For pre-hybridization embryos were incubated in $\mathrm{L}^{-}$Buffer $(50 \%$ Formamide, $5 \mathrm{x}$ SSC $\mathrm{pH} 4.5,1 \%$ SDS and $0,1 \%$ Tween-20) for $10 \mathrm{~min}$ at $68^{\circ} \mathrm{C}$. Then embryos were incubated in H1-Buffer (L1-Buffer supplemented with $0,1 \mathrm{mg} / \mathrm{ml}$ tRNA and 0,05 $\mathrm{mg} / \mathrm{ml} \mathrm{Heparin)}$ for $2 \mathrm{~h}$ at $68^{\circ} \mathrm{C}$. Riboprobes were diluted in $\mathrm{H} 1-\mathrm{Buffer}$ and added to embryos in $2 \mathrm{ml}$ cryovials followed by hybridisation at $68^{\circ} \mathrm{C}$ overnight. Unbound probe was removed by washing the embryos 3 times for $30 \mathrm{~min}$ in $68^{\circ} \mathrm{C}$ in pre-warmed L1-Buffer followed by 3 times washing in L2-Buffer $(50 \%$ Formamid, $2 \mathrm{x}$ SSC $\mathrm{pH} 4.5,0,1 \%$ Tween-20 in DEPC-water) for $30 \mathrm{~min}$ at $68^{\circ} \mathrm{C}$. Embryos were then washed for $15 \mathrm{~min}$ at $68^{\circ} \mathrm{C}$ with L3-Buffer (L3-Buffer: $2 x$ SSC $\mathrm{pH} 4.5,0,1 \%$ Tween-20 in DEPC water) followed by washing in a $1: 1$ solution of L3-Buffer and RNase buffer (500 $\mathrm{mM} \mathrm{NaCl}, 10 \mathrm{mM}$ Tris $\mathrm{pH} 7.5,0,1 \%$ Tween-20) for $5 \mathrm{~min}$ at room temperature. Embryos were treated with a solution of $100 \mu \mathrm{g} / \mathrm{ml}$ RNase A in RNase buffer for $1 \mathrm{~h}$ at $37^{\circ} \mathrm{C}$. RNase solution was washed out 3 times for $5 \mathrm{~min}$ each at room temperature with Tris saline buffer $(8 \mathrm{~g} / \mathrm{L} \mathrm{NaCl}, 0,2 \mathrm{~g} / \mathrm{L}$
$\mathrm{KCl}, 3 \mathrm{~g} / \mathrm{L}$ Tris pH 7.4) supplemented with 1\% Tween-20. Embryos were blocked in blocking solution ( $2 \%$ fetal calf serum, $2 \mathrm{mg} / \mathrm{ml}$ bovine serum albumin dissolved in TBST) at room temperature for $2 \mathrm{~h}$. Anti-DIG antibody (Roche: 11093274910) was dissolved 1:5000 in blocking solution and incubated overnight under rotation at $4^{\circ}$ C. Embryos were washed in TBST supplemented with alkaline phosphatase inhibitors 0,05\% Levamisole/Tetramisole (Sigma Aldrich L9756) 5 times for $5 \mathrm{~min}$ each, and again 8 times for $30 \mathrm{~min}$ each. Embryos were then incubated in alkaline phosphatase buffer $\left(100 \mu \mathrm{M} \mathrm{NaCl}, 50 \mathrm{mM} \mathrm{MgCl}_{2}, 0,1 \%\right.$ Tween-20, $100 \mathrm{mM}$ Tris pH 9.5 and $0,5 \mathrm{mg} / \mathrm{ml}$ Levamisole/Tetramisole) for $20 \mathrm{~min}$. Signal detection was performed with $225 \mu \mathrm{g} / \mathrm{ml} \mathrm{NBT}$ and $87,5 \mu \mathrm{g} / \mathrm{ml}$ BCIP dissolved in alkaline phosphate buffer at room temperature under light protection. Signal development was stopped by washing for 3 times 10 min each in alkaline phosphate buffer followed by fixation in $4 \%$ PFA, $0,2 \%$ glutaraldehyde and 5 mM EDTA for long term storage.

Cell isolation and flow cytometry. Limbs of E13.5 $\mathrm{Osr} 1^{G C E /+}$ or $\mathrm{Osr1} 1^{G C E / G C E}$ embryos were minced in $500 \mu \mathrm{L}$ high-glucose Dulbecco's modified eagle medium (DMEM, Invitrogen) using a small scissor. Further enzymatic digestion of the tissue was performed using $10 \mathrm{mg} \mathrm{ml}^{-1}$ of Collagenase (Collagenase NB $4 \mathrm{G}$ proved grade, SERVA Electrophoresis ${ }^{\mathrm{TM}}$ ) in DMEM medium supplemented with $2 \mathrm{mM}$ $\mathrm{CaCl}_{2}$ and $\mathrm{MgCl}_{2}$ with vigorous shaking at $37^{\circ} \mathrm{C}$ for $45 \mathrm{~min}$. After digestion, tissue extracts were washed and resuspended in high-glucose DMEM medium. Cell suspensions were passed through a $100-\mu \mathrm{m}$ cell strainer (Miltenyl Biotec) and collected by centrifugation at $300 \mathrm{~g}$ for $5 \mathrm{~min}$. For flow cytometry analysis or cell sorting, cell suspensions were blocked for $5 \mathrm{~min}$. in $5 \%$ mouse serum (Sigma Aldrich). Antibody labelling (antibodies see Supplementary Table 3) was performed for $60 \mathrm{~min}$ at $4{ }^{\circ} \mathrm{C}$. Before flow cytometry cell suspensions were washed, collected by centrifugation at $300 \mathrm{~g}$ for $5 \mathrm{~min}$ and passed through a $35-\mu \mathrm{m}$ cell strainer filter (BD Biosciences). To assess viability, cells were stained with propidium iodide ( $1 \mu \mathrm{g} \mathrm{ml}^{-1}$, eBioscience) immediately before sorting or analysis.

For cell isolation from adult muscles whole hind limb muscles were carefully isolated, roughly minced and digested in high-glucose DMEM medium containing $2,5 \mathrm{mg} / \mathrm{ml}$ Collagenase A (Roche) for $75 \mathrm{~min}$ at $37^{\circ} \mathrm{C}$ with vigorous shaking. $2 \mathrm{IU} /$ $\mathrm{ml}$ of Dispase II (Sigma Aldrich) were added to the digestion solution and muscle lysates were digested for further $30 \mathrm{~min}$. Muscle slurries were passed 10 times through a $20 \mathrm{G}$ syringe (BD Bioscience) and a $70-\mu \mathrm{m}$ cell strainer. Cells were collected by centrifugation at $300 \mathrm{~g}$ for $5 \mathrm{~min}$ and resuspended in staining buffer consisting of $500 \mu \mathrm{l}$ Hank's balanced salt solution (HBSS, Thermo Fisher scientific) $0.4 \%$ bovine serum albumin (Sigma Aldrich) and $20 \mu \mathrm{g} / \mathrm{ml}$ Gentamycin (Serva Electrophoresis). Cells were labelled with antibodies (Supplementary Table 6) on ice for $30 \mathrm{~min}$ and washed twice with staining buffer previous to FACS sorting. Propidium iodide was used as a viability dye.

Sorts and analyses were performed on a FACS Aria II (BD Biosciences). Data were collected using FACSDIVA software. Biexponential analyses were performed using FlowJo 10 (FlowJo LLC) software. Analysis was performed on three independent biological replicates (i.e. cells FACS isolated from three different embryos). Sorting gates were defined based on unstained controls. Cells were sorted either into $1 \mathrm{ml}$ high-glucose DMEM warmed to $37^{\circ} \mathrm{C}$ for further culturing or directly into buffer RLT (Qiagen RNeasy kit) for RNA extraction.

Cell culture. FACS isolated cells were collected by centrifugation at $300 \mathrm{~g}$ for $5 \mathrm{~min}$ and seeded on $2 \%$ Matrigel $^{\mathrm{TM}}$ (BD Biosciences) coated glass coverslips (Thermo scientific) previously exposed to $30 \mathrm{~min}$ of UV light. Before differentiation induction cells were then expanded for 3 days in growth medium (high-glucose DMEM medium with $10 \%$ fetal bovine serum (FBS, Biochrom)). FACS isolated cells designated for adipogenic differentiation were first expanded for 3 days in medium containing 60\% low-glucose DMEM (Invitrogen), 40\% MCDB201 Media (Sigma Aldrich), 10\% FBS, $0.4 \mathrm{ng} \mathrm{mL}^{-1}$ dexamethasone, $29 \mu \mathrm{g} \mathrm{mL}^{-1} \mathrm{~L}$-ascorbic acid 2-phosphate, 1x ITS liquid media supplemented mix, 1x Linoleic acid-albumin (Sigma Aldrich) and freshly added growth factors: $10 \mathrm{ng} \mathrm{mL}{ }^{-1}$ EGF, $10 \mathrm{ng} \mathrm{mL}^{-1}$

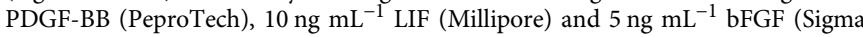
Aldrich).

Myogenic differentiation was induced by culturing cells for 5-7 days in highglucose DMEM medium with $2 \%$ horse serum (Vector Labs). For fibrogenic differentiation cells were cultured in low-glucose DMEM medium with $2 \%$ FBS supplemented with $1 \mathrm{ng} \mathrm{mL} \mathrm{m}^{-1}$ TGF $\beta 1$ (PeproTech) for 3 days followed by 3 days in differentiation medium without TGF $\beta 1$. For osteogenic differentiation, we used low-glucose DMEM medium supplemented with $100 \mathrm{nM}$ dexamethasone, $10 \mathrm{mM}$ $\beta$-glycerophosphate, $0.2 \mathrm{mM}$ ascorbic acid and $50 \mathrm{ng} \mathrm{ml}^{-1} \mathrm{~L}$-thyroxine (Sigma Aldrich) and differentiated the cells for 40 days with medium change every two days. For chondrogenic differentiation we seeded $20 \mu$ droplets of $10^{5}$ cell suspensions on uncoated coverslips. Cultures were grown in high-glucose DMEM medium with $10 \%$ FBS and supplemented with $10 \mathrm{ng} \mathrm{mL}^{-1} \mathrm{TGF} \beta 1,1 \mu \mathrm{M}$ ascorbic acid, $100 \mathrm{nM}$ dexamethasone and 10x ITS liquid media supplemented mix (Sigma Aldrich) for 14 days. Medium was changed every 2-4 days. For adipogenic differentiation cells were cultured for $48 \mathrm{~h}$ in $60 \%$ low-glucose DMEM (Invitrogen), $40 \%$ MCDB201 Media (Sigma Aldrich), 10\% FBS supplemented with $1 \mu \mathrm{M}$ dexamethasone, $0.5 \mu \mathrm{M}$ isobutylmethylxanthine, $5 \mu \mathrm{gL}^{-1}, 50 \mu \mathrm{M}$ indomethacin, $1 \mathrm{nM}$ triiodo-L-thyronine sodium salt (Sigma Aldrich) and insulin (Roche). Thereafter cells were cultured for 7 days in 60\% low-glucose DMEM (Invitrogen), 
40\% MCDB201 (Sigma Aldrich), 10\% FBS. Differentiation assays were performed on three independent biological replicates (i.e. cells FACS isolated from three different embryos).

ECM deposition assay was conducted as follows: $\mathrm{Osr}^{+}$cells were isolated via FACS sorting from E13.5 Osr1 $1^{\mathrm{GCE} /+}$ or Osr1 ${ }^{\mathrm{GCE} / \mathrm{GCE}}$ embryos and plated on 24 well-plates (52.500 cells/well). Cells were kept in growth medium (10\% FCS, DMEM 4,5 g Glucose, 1\% Penicillin/Streptomycin, 1\% L-Glutamine) until they reached $80 \%$ confluence. Cells were further cultured in low serum medium $(2 \%$ FCS, DMEM 4,5 g Glucose, $1 \%$ Penicillin/Streptomycin, $1 \%$ L-Glutamine) for 14 days. Decellularization was conducted via a snap freeze/thaw procedure. Cells were washed once with $\mathrm{H}_{2} \mathrm{O}$, then wells were filled with $200 \mu \mathrm{l}$ of $\mathrm{H}_{2} \mathrm{O}$ and plates were stored for $40 \mathrm{~min}$ at $-80^{\circ} \mathrm{C}$. Plates were thawed in a $37^{\circ} \mathrm{C}$ water bath for $30 \mathrm{~s}$. Then the wells were filled with $800 \mu \mathrm{l}$ growth medium (room temperature) and transferred to $37^{\circ} \mathrm{C}$. Myoblasts were collected from 3-4 days old neonate mice via FACS $\left(\mathrm{CD}^{-} 5^{-} ; \mathrm{CD}^{-} 1^{-} ; \mathrm{Ter}_{119^{-} ; \mathrm{Scal}^{-} ; \alpha 7 \text {-integrin }}{ }^{+}\right)$. Myoblasts were seeded on the ECM $\left(2,5 \times 10^{5}\right.$ cells/well). As control Myoblasts were seeded in wells coated with $10 \%$ Matrigel (Corning). Myoblasts were then cultured in proliferation medium (20\% FCS, 10\% horse serum, DMEM 4,5 g Glucose, 1\% Penicillin/Streptomycin, $1 \%$ L-Glutamine) for $16 \mathrm{~h}$. Then cells were fixed with $4 \%$ PFA and immunolabeled for Pax7 and Ki67.

Transwell assay was performed as follows: $2,5 \times 10^{5}$ FACS-isolated p3-4 myoblasts (see above) were seeded on glass coverslips coated with Matrigel ${ }^{\mathrm{TM}}$ and allowed to settle for $24 \mathrm{~h}$ in myogenic proliferation medium (DMEM 4,5 g Glucose, $1 \%$ Penicillin/Streptomycin, 1\% L-Glutamine, 10\% horse serum, 20\% FBS) in 24 well plates. The day before $\mathrm{Osr}^{+}{ }^{+}$cells were isolated via FACS from E13.5 Osr1 ${ }^{\mathrm{GCE} /}$ ${ }^{+}$or Osr1 ${ }^{\mathrm{GCE} / \mathrm{GCE}}$ embryos. $8 \times 10^{4} \mathrm{GFP}^{+}$cells were seeded into transwell inserts and cultured for $24 \mathrm{~h}$ in growth medium. On the next day, growth medium was replaced by myogenic differentiation medium (DMEM 4,5 g Glucose, $1 \%$ Penicillin/Streptomycin, $1 \%$ L-Glutamine, $2 \%$ horse serum) for preconditioning. After $24 \mathrm{~h}$ the transwell inserts containing the $\mathrm{GFP}^{+}$cells together with the preconditioned myogenic differentiation medium were transferred to 24 well plates containing the myoblasts. As control, myoblasts were cultured with empty transwell inserts. Transwell coculture was performed for 14 days with medium change every second day. Myogenic differentiation was analyzed by immunolabeling for Myosin heavy chain (MyHC). For quantification an area of $1,75 \mathrm{~mm}^{2}$ were analyzed and only $\mathrm{MyHC}^{+} \mathrm{DAPI}^{+}$cells were counted.

Staining procedures. To stain lipids, cell cultures were stained with Oil Red O (Sigma Aldrich) $0.5 \%$ (w/v) $1 \mathrm{~h}$ at RT. Lipids on sections were stained $15 \mathrm{~min}$ in Oil Red O staining solution at RT. Calcium accumulation after osteogenic differentiation was assessed by Alizarin Red (Sigma Aldrich) staining using a 1\% (v/v) staining solution (from a stock solution of $13.3 \mathrm{mg} \mathrm{mL}^{-1}$ at $\mathrm{pH}$ 6.5) applied during $30 \mathrm{~min}$. For assessing chondrogenic differentiation cultures were stained using Alcian Blue (Sigma Aldrich) staining solution $10 \mathrm{mg} \mathrm{mL}^{-1}$ dissolved in $0.1 \mathrm{~N}$ hydrochloric acid (Carl Roth) applied during $30 \mathrm{~min}$ at RT.

Imaging. Cell cultures were documented with a Nikon Eclipse TS 100 microscope, a Leica DMR microscope or a Zeiss SteREO Discovery V12 stereomicroscope. Confocal images of immunolabelled sections or cells were taken using the confocal laser scanning microscope system LSM710 (Zeiss). Images were captured using Axio Vission Rel. 4.8 and Zen 2010 (Zeiss).

Cell quantification. Quantification of FACS-isolated $\mathrm{Osrl}^{+}$cells after immunolabelling (cytospin or growth medium culture) was performed on three independent biological replicates (i.e. cells FACS isolated from three different embryos). Quantification of specific cell markers on sections after immunolabelling was assessed on at least 4 serial sections in $30 \mu \mathrm{m}$ intervals for each biological replicate with a minimum of 3 replicates (exact values given in figures, in each case $n$ stands for one biological replicate). In Fig. $3 \mathrm{~g}$ the interval was reduced to $10 \mu \mathrm{m}$. For each experiment serial sections of the whole limb were immunolabelled, and only sections containing comparable regions were used for quantification. At least five sections for each biological replicate were counted. Student's t-test was performed using Prism 5 (GraphPad) software. Error bars in all figures, including supplementary information, represent the mean \pm standard error of the mean (s.e.m).

3D reconstruction of embryonic limb muscles. Whole mount immunofluorescence labelling on E14.5 embryonic limbs was performed as previously described $^{65}$. For 3D reconstruction, images captured on a LSM710 confocal microscope (Zeiss) were analysed using the programs Amira ${ }^{\circledR}$ (FEI visualization Sciences Group) and Fluorender ${ }^{\circledR}$ (University of Utah).

Quantitative real-time PCR. RNA isolation was performed using RNeasy mini kits (Qiagen), and RNA quantification was assessed using a ND2000 spectrophotometer (Nanodrop). Reverse transcription was performed using the High Capacity cDNA Reverse Transcription Kit (Applied Biosystems). Gene expression analysis was conducted using Taqman Gene Expression Assays (Applied
Biosystems), on a 7900HT Real Time PCR system (Applied Biosystems). Primer sequence information is provided in Supplementary Table 7. Data were acquired and analysed using SDS 2.0 software (Applied Biosystems). Quantitative RT-PCR analyses were performed on at least four independent biological samples (embryos) different from those used for RNA-Sequencing.

RNA-sequencing. Total RNAs were extracted from $\mathrm{Osrl}^{+}$cells isolated by FACS sorting from E13.5 limbs of two Osr $1^{G C E /+}$ and two $O s r 1^{G C E / G C E}$ embryos by using the RNeasy mini kit (Qiagen). Libraries were prepared by using the TruSeq RNA Library Preparation Kit v2 according to Illumina's intructions and subjected to high-throughput sequencing by using the Illumina HiSeq 2500 technology. 65-75 million of 50-bp paired-end reads were generated with a mean insert size of $150 \mathrm{bp}$ and mapped against the genome of Mus musculus version mm9 by using

TopHat $2^{66}$ and the UCSC gene model annotation from iGenome as guide (default parameters, except for the mean inner distance set at 150 and the minimum intron length set at 50). Aligned fragments per gene were counted by using the intersection strict mode from $\mathrm{HTSeq}^{67}$. Raw fragment counts showed a very high Pearson correlation $(>0.99)$ between both biological replicates for each condition Differential expression analysis was performed by using DESeq2 ${ }^{68}$ and a false discovery rate (FDR; alpha) of 0.05 . Genes were considered as being differentially expressed between the Osr1 ${ }^{\mathrm{GCE} /+}$ and $\mathrm{Osr} 1^{\mathrm{GCE} / \mathrm{GCE}}$ conditions if the BenjaminiHochberg adjusted $p$-value (padj) was below 0.1. Transcripts per million (TPM) abundances were calculated from the mean normalized fragment counts given by $\mathrm{DESeq} 2$ for both Osr1 ${ }^{\mathrm{GCE} / \mathrm{GCE}}$ samples. Gene ontology $(\mathrm{GO})$ analyses were carried out by using the DAVID functional annotation tools ${ }^{69}$. Raw fastq and count data were uploaded on the Gene Expression Omnibus (GEO) database under the accession number GSE78056.

Chromatin immunoprecipitation. Genomic regions up to $20 \mathrm{~kb}$ upstream of putative direct Osrl targets were screened for consensus Osrl binding sites in the UCSC browser (GRCm38/mm10). For Cxcl12, in addition the gene desert $5^{\prime}$ of the first exon was screened for Osr1 binding sites specifically within DNAseI hypersensitive regions (putative enhancers). Distant binding sites were confirmed to be included into the same topology-associated domain as Cxcl12 (http://promoter.bx. psu.edu/hi-c/view.php $)^{70}$ PCR primer were designed overlapping or closely adjacent to binding sites. Regions without consensus binding sites located in the vicinity were chosen as controls.

Lentiviral particles carrying an Osr1-tripleFLAG construct under the ubiquitin $c(\mathrm{UbC})$ promoter or carrying a GFP expression construct as control were purchased from AMSBio (Abingdon, UK). For ChIP assays, MEFs were isolated from E13.5 C57Bl6 limbs as described above (Cell isolation). For infection $3 \times$ $10^{5}-4 \times 10^{5}$ cells were resuspended in $5 \mathrm{ml} 37^{\circ} \mathrm{C}$ pre-warmed growth medium (high glucose DMEM medium supplemented with 10\% FBS). Infection was achieved using spinoculation of suspension cells. Polybrene and lentoviral particles were added to the medium. Cells and virus particles were centrifuged for $60 \mathrm{~min}$ at $300 \mathrm{~g}$ before seeding. Medium was changed at the next day. Chromatin immunoprecipitation (ChIP) was performed as follows: cells were fixed on a confluent $10 \mathrm{~cm}$ dish for $10 \mathrm{~min}$ with $10 \mathrm{ml}$ of $1 \%$ Formaldehyde (Sigma Aldrich) in growth medium. Chromatin cross-linking was quenched adding $550 \mu \mathrm{l}$ of $2.5 \mathrm{M}$ Glycine. Medium was removed and cells were washed twice with DPBS. Cells were lysed and removed with a scratcher. Nuclei were collected in $900 \mu$ sonication buffer and split into $3 \times 1.5 \mathrm{ml}$ TPX tubes (Biogenade). Cells were sonicated for 20 cycles in a Bioruptor (Biogenade). $30 \mu \mathrm{g}$ of sonicated chromatin was used per ChIP $8 \mu \mathrm{g}$ of anti-FLAG antibody was added to the $30 \mu \mathrm{g}$ of sonicated chromatin and incubated under rotation overnight at $4{ }^{\circ} \mathrm{C} .30 \mu \mathrm{l}$ of protein $\mathrm{G}$ beads (Invitrogen) were added to the Chromatin-Antibody mixture and incubated under rotation at 4 ${ }^{\circ} \mathrm{C}$ overnight. Chromatin bound to the Dynabeads-antibody complex was isolated using vigorously shaking conditions at $65^{\circ} \mathrm{C}$ for $30 \mathrm{~min}$ and further de-crosslinked overnight at $65^{\circ} \mathrm{C}$. Proteins bound to the chromatin were removed with a $60 \mathrm{~min}$ treatment at $55^{\circ} \mathrm{C}$ of Proteinase $\mathrm{K}(500 \mathrm{mg} / \mathrm{ml})$ and RNA with a 30 min treatment at $37^{\circ} \mathrm{C}$ with RNase A (Sigma Aldrich). Genomic DNA from sonicated chromatin was used as an input DNA and DNA isolated after ChIP as pulldown DNA. Pulldown was evaluated by Gel electrophoresis and quantitative real-time PCR with 3 independent pulldown experiments. Primer sequences are provided in Supplementary Table 8. Uncropped lanes from representative gel electrophoresis images can be found in Supplementary Fig. 12.

Data availability. All data supporting the findings of this study are available within the article and its supplementary information files or from the corresponding author upon reasonable request. Raw fastq and count data from RNA Sequencing experiments have been deposited in the Gene Expression Omnibus (GEO) database under accession code GSE78056.

Received: 4 April 2016 Accepted: 17 August 2017 Published online: 31 October 2017 


\section{References}

1. Christ, B., Jacob, H. J. \& Jacob, M. Experimental analysis of the origin of the wing musculature in avian embryos. Anat. Embryol. (Berl). 150, 171-186 (1977).

2. Chevallier, A., Kieny, M. \& Mauger, A. Limb-somite relationship: origin of the limb musculature. J. Embryol. Exp. Morphol. 41, 245-258 (1977).

3. Schienda, J. et al. Somitic origin of limb muscle satellite and side population cells. Proc. Natl Acad Sci. USA 103, 945-950 (2006).

4. Duprez, D. Signals regulating muscle formation in the limb during embryonic development. Int. J. Dev. Biol. 46, 915-925 (2002).

5. Murphy, M. \& Kardon, G. Origin of vertebrate limb muscle: the role of progenitor and myoblast populations. Curr. Top. Dev. Biol. 96, 1-32 (2011).

6. Ordahl, C. P. \& Le Douarin, N. M. Two myogenic lineages within the developing somite. Development 114, 339-353 (1992).

7. Lance-Jones, C. The somitic level of origin of embryonic chick hindlimb muscles. Dev. Biol. 126, 394-407 (1988).

8. Chevallier, A. \& Kieny, M. On the role of the connective tissue in the patterning of the chick limb musculature. Wilhelm Roux's Archives 191, 277-280 (1982).

9. Shellswell, G. B., Bailey, A. J., Duance, V. C. \& Restall, D. J. Has collagen a role in muscle pattern formation in the developing chick wing? 1. An immunofluorescence study. J Embryol Exp Morphol 60, 245-254 (1980)

10. Kardon, G., Campbell, J. K. \& Tabin, C. J. Local extrinsic signals determine muscle and endothelial cell fate and patterning in the vertebrate limb. Dev. Cell. 3, 533-545 (2002).

11. Kardon, G., Harfe, B. D. \& Tabin, C. J. A Tcf4-positive mesodermal population provides a prepattern for vertebrate limb muscle patterning. Dev. Cell. 5, 937-944 (2003).

12. Mathew, S. J. et al. Connective tissue fibroblasts and Tcf4 regulate myogenesis. Development 138, 371-384 (2011).

13. Hasson, P. "Soft" tissue patterning: muscles and tendons of the limb take their form. Dev. Dyn. 240, 1100-1107 (2011).

14. Murphy, M. M., Lawson, J. A., Mathew, S. J., Hutcheson, D. A. \& Kardon, G. Satellite cells, connective tissue fibroblasts and their interactions are crucial for muscle regeneration. Development 138, 3625-3637 (2011).

15. Pannerec, A., Formicola, L., Besson, V., Marazzi, G. \& Sassoon, D. A. Defining skeletal muscle resident progenitors and their cell fate potentials. Development 140, 2879-2891 (2013).

16. Judson, R. N., Zhang, R. H. \& Rossi, F. M. Tissue-resident mesenchymal stem/ progenitor cells in skeletal muscle: collaborators or saboteurs? FEBS. J. 280, 4100-4108 (2013).

17. Pannerec, A., Marazzi, G. \& Sassoon, D. Stem cells in the hood: the skeletal muscle niche. Trends. Mol. Med. 18, 599-606 (2012).

18. Malecova, B. \& Puri, P. L. "Mix of mics"- phenotypic and biological heterogeneity of "multipotent" muscle interstitial cells (MICs). J Stem Cell Res Ther S11, 004 (2012).

19. Uezumi, A., Ikemoto-Uezumi, M. \& Tsuchida, K. Roles of nonmyogenic mesenchymal progenitors in pathogenesis and regeneration of skeletal muscle. Frontiers in physiology 5, 68 (2014).

20. Joe, A. W. et al. Muscle injury activates resident fibro/adipogenic progenitors that facilitate myogenesis. Nat. Cell. Biol. 12, 153-163 (2010).

21. Uezumi, A., Fukada, S., Yamamoto, N., Takeda, S. \& Tsuchida, K. Mesenchymal progenitors distinct from satellite cells contribute to ectopic fat cell formation in skeletal muscle. Nat. Cell. Biol. 12, 143-152 (2010).

22. Uezumi, A. et al. Fibrosis and adipogenesis originate from a common mesenchymal progenitor in skeletal muscle. J. Cell. Sci. 124, 3654-3664 (2011).

23. Stricker, S. et al. Odd-skipped related genes regulate differentiation of embryonic limb mesenchyme and bone marrow mesenchymal stromal cells. Stem. Cells. Dev. 21, 623-633 (2012).

24. Stricker, S., Brieske, N., Haupt, J. \& Mundlos, S. Comparative expression pattern of Odd-skipped related genes Osr1 and Osr2 in chick embryonic development. Gene. Expr. Patterns. 6, 826-834 (2006).

25. Mugford, J. W., Sipila, P., McMahon, J. A. \& McMahon, A. P. Osr1 expression demarcates a multi-potent population of intermediate mesoderm that undergoes progressive restriction to an Osr1-dependent nephron progenitor compartment within the mammalian kidney. Dev. Biol. 324, 88-98 (2008).

26. Uezumi, A. et al. Identification and characterization of PDGFRalpha+ mesenchymal progenitors in human skeletal muscle. Cell Death Dis 5, e1186 (2014).

27. Miles, C., Sanchez, M. J., Sinclair, A. \& Dzierzak, E. Expression of the Ly-6E.1 (Sca-1) transgene in adult hematopoietic stem cells and the developing mouse embryo. Development 124, 537-547 (1997).

28. Diez-Roux, G. et al. A high-resolution anatomical atlas of the transcriptome in the mouse embryo. PLoS Biol. 9, e1000582 (2011).

29. Wang, Q., Lan, Y., Cho, E. S., Maltby, K. M. \& Jiang, R. Odd-skipped related 1 (Odd 1) is an essential regulator of heart and urogenital development. Dev. Biol. 288, 582-594 (2005).

30. Havis, E. et al. Transcriptomic analysis of mouse limb tendon cells during development. Development 141, 3683-3696 (2014).
31. Gao, Y., Lan, Y., Liu, H. \& Jiang, R. The zinc finger transcription factors Osr1 and Osr2 control synovial joint formation. Dev. Biol. 352, 83-91 (2011).

32. Liu, H. et al. Odd-skipped related-1 controls neural crest chondrogenesis during tongue development. Proc. Natl Acad Sci. USA 110, 18555-18560 (2013).

33. Bonnemann, C. G. The collagen VI-related myopathies: muscle meets its matrix. Nat Rev Neurol 7, 379-390 (2011).

34. Merline, R., Schaefer, R. M. \& Schaefer, L. The matricellular functions of small leucine-rich proteoglycans (SLRPs). J. Cell. Commun. Signal. 3, 323-335 (2009).

35. Badis, G. et al. Diversity and complexity in DNA recognition by transcription factors. Science 324, 1720-1723 (2009).

36. Meng, X., Brodsky, M. H. \& Wolfe, S. A. A bacterial one-hybrid system for determining the DNA-binding specificity of transcription factors. Nat. Biotechnol. 23, 988-994 (2005).

37. Kent, W. J. et al. The human genome browser at UCSC. Genome Res. 12, 996-1006 (2002).

38. Lamande, S. R. et al. The role of the alpha3(VI) chain in collagen VI assembly. Expression of an alpha3(VI) chain lacking N-terminal modules N10-N7 restores collagen VI assembly, secretion, and matrix deposition in an alpha3 (VI)-deficient cell line. J. Biol. Chem. 273, 7423-7430 (1998).

39. Pan, T. C. et al. COL6A3 protein deficiency in mice leads to muscle and tendon defects similar to human collagen VI congenital muscular dystrophy. J. Biol. Chem. 288, 14320-14331 (2013).

40. Sabatelli, P. et al. Collagen VI deficiency affects the organization of fibronectin in the extracellular matrix of cultured fibroblasts. Matrix. Biol. 20, 475-486 (2001).

41. Ehnis, T., Dieterich, W., Bauer, M., Kresse, H. \& Schuppan, D. Localization of a binding site for the proteoglycan decorin on collagen XIV (undulin). J. Biol. Chem. 272, 20414-20419 (1997).

42. Gullberg, D. \& Ekblom, P. Extracellular matrix and its receptors during development. Int. J. Dev. Biol. 39, 845-854 (1995).

43. Garcia, A. J., Vega, M. D. \& Boettiger, D. Modulation of cell proliferation and differentiation through substrate-dependent changes in fibronectin conformation. Mol. Biol. Cell. 10, 785-798 (1999).

44. Xing, Q. et al. Decellularization of fibroblast cell sheets for natural extracellular matrix scaffold preparation. Tissue. Eng. Part. C. Methods. 21, 77-87 (2015).

45. Bonaldo, P. et al. Collagen VI deficiency induces early onset myopathy in the mouse: an animal model for Bethlem myopathy. Hum. Mol. Genet. 7, 2135-2140 (1998).

46. Griffin, C. A., Apponi, L. H., Long, K. K. \& Pavlath, G. K. Chemokine expression and control of muscle cell migration during myogenesis. J. Cell. Sci. 123, 3052-3060 (2010).

47. Hunger, C., Odemis, V. \& Engele, J. Expression and function of the SDF-1 chemokine receptors CXCR4 and CXCR7 during mouse limb muscle development and regeneration. Exp. Cell. Res. 318, 2178-2190 (2012).

48. Vasyutina, E., Stebler, J., Brand-Saberi, B., Schulz, S. \& Raz, E. Birchmeier C. CXCR4 and Gab1 cooperate to control the development of migrating muscle progenitor cells. Genes Dev. 19, 2187-2198 (2005).

49. Odemis, V. et al. Mice deficient in the chemokine receptor CXCR4 exhibit impaired limb innervation and myogenesis. Mol. Cell. Neurosci. 30, 494-505 (2005).

50. Thorsteinsdottir, S., Deries, M., Cachaco, A. S. \& Bajanca, F. The extracellular matrix dimension of skeletal muscle development. Dev. Biol. 354, 191-207 (2011).

51. Zhao, P. et al. Anoctamin 6 regulates C2C12 myoblast proliferation. PLoS ONE 9, e92749 (2014).

52. Schwartz, M. A. \& Assoian, R. K. Integrins and cell proliferation: regulation of cyclin-dependent kinases via cytoplasmic signaling pathways. J. Cell. Sci. 114, 2553-2560 (2001).

53. Kadler, K. E., Hill, A. \& Canty-Laird, E. G. Collagen fibrillogenesis: fibronectin, integrins, and minor collagens as organizers and nucleators. Curr. Opin. Cell. Biol. 20, 495-501 (2008).

54. Amthor, H., Christ, B., Weil, M. \& Patel, K. The importance of timing differentiation during limb muscle development. Curr. Biol. 8, 642-652 (1998)

55. Wang, H. et al. Bmp signaling at the tips of skeletal muscles regulates the number of fetal muscle progenitors and satellite cells during development. Dev. Cell. 18, 643-654 (2010).

56. Doring, Y., Pawig, L., Weber, C. \& Noels, H. The CXCL12/CXCR4 chemokine ligand/receptor axis in cardiovascular disease. Frontiers in physiology 5, 212 (2014).

57. Tsang, K. Y., Cheung, M. C., Chan, D. \& Cheah, K. S. The developmental roles of the extracellular matrix: beyond structure to regulation. Cell. Tissue. Res. 339, 93-110 (2010).

58. Hasson, P. et al. Tbx 4 and tbx 5 acting in connective tissue are required for limb muscle and tendon patterning. Dev. Cell. 18, 148-156 (2010).

59. Swinehart, I. T., Schlientz, A. J., Quintanilla, C. A., Mortlock, D. P. \& Wellik, D. M. Hox11 genes are required for regional patterning and integration of muscle, tendon and bone. Development 140, 4574-4582 (2013) 
60. Bentzinger, C. F., Wang, Y. X., Dumont, N. A. \& Rudnicki, M. A. Cellular dynamics in the muscle satellite cell niche. EMBO. Rep. 14, 1062-1072 (2013).

61. Hayashi, S., Rocancourt, D., Buckingham, M. \& Relaix, F. Lack of in vivo functional compensation between Pax family groups II and III in rodents. Mol. Biol. Evol. 28, 2787-2798 (2011).

62. Muzumdar, M. D., Tasic, B., Miyamichi, K., Li, L. \& Luo, L. A global doublefluorescent Cre reporter mouse. Genesis. 45, 593-605 (2007).

63. Soriano, P. Generalized lacZ expression with the ROSA26 Cre reporter strain. Nat. Genet. 21, 70-71 (1999).

64. Zou, Y. R., Kottmann, A. H., Kuroda, M., Taniuchi, I. \& Littman, D. R. Function of the chemokine receptor CXCR4 in haematopoiesis and in cerebellar development. Nature. 393, 595-599 (1998).

65. Merrell, A. J. et al. Muscle connective tissue controls development of the diaphragm and is a source of congenital diaphragmatic hernias. Nat. Genet. 47, 496-504 (2015).

66. Kim, D. et al. TopHat2: accurate alignment of transcriptomes in the presence of insertions, deletions and gene fusions. Genome. Biol. 14, R36 (2013).

67. Anders, S., Pyl, P. T. \& Huber, W. HTSeq--a python framework to work with high-throughput sequencing data. Bioinformatics. 31, 166-169 (2015).

68. Love, M. I., Huber, W. \& Anders, S. Moderated estimation of fold change and dispersion for RNA-seq data with DESeq2. Genome. Biol. 15, 550 (2014).

69. Huang da, W., Sherman, B. T. \& Lempicki, R. A. Systematic and integrative analysis of large gene lists using DAVID bioinformatics resources. Nat. Protoc. 4, 44-57 (2009).

70. Dixon, J. R. et al. Topological domains in mammalian genomes identified by analysis of chromatin interactions. Nature. 485, 376-380 (2012).

\section{Acknowledgements}

This work was funded by the German Research Foundation (DFG; grant GK1631), French-German University (UFA-DFH; grant CDFA-06-11), the Association Française contre les Myopathies (AFM 16826), and the Fondation pour la Recherche Médicale (FRM DEQ20140329500) as part of the MyoGrad International Research Training Group for Myology. This work was funded by a grant from the AFM to D.D. and S.S. (Grant No. 18626), a grant from the FRM (grant No. FDT20150532272) to M.O., and by the Focus Area DynAge of the Freie Universität Berlin. We gratefully acknowledge Andrew P. McMahon (Harvard Medical School, USA) and Andreas Kispert (Hannover Medical School, Germany) for providing $O s r 1^{G C E}$ and $\mathrm{R} 26^{\mathrm{mTmG}}$ mouse lines, and Carmen Birchmeier (Max Delbrueck Centre, Berlin, Germany) for $\mathrm{Cxcr}^{+/-}$mice, antibodies and technical advice. We thank Tim J. Schultz (German Institute of Human Nutrition, Potsdam) for advice on cell differentiation assays. We thank Petra
Knaus and Christian Hiepen (Institute for Chemistry and Biochemistry, Freie Universität Berlin) for advice on the ECM assay.

\section{Author contributions}

Experiments were conceived and designed by S.S., D.D. and P.V.G. P.V.G. performed the majority of experiments and data collection. S.vH.S., J.S., V.K. and D.M.I. performed experiments and analysed data. S.T.B. and B.T. performed and supervised the RNASequencing procedure and M.O. performed RNA Sequencing data analysis. S.H., F.R., K.H., G.S. and M.K. provided reagents and mouse mutants. Data analysis and interpretation was performed by P.V.G. and S.S. with involvement of G.M., D.S. and D.D. S.S. D.D. and D.S. wrote the manuscript.

\section{Additional information}

Supplementary Information accompanies this paper at doi:10.1038/s41467-017-01120-3.

Competing interests: The authors declare no competing financial interests.

Reprints and permission information is available online at http://npg.nature.com/ reprintsandpermissions/

Publisher's note: Springer Nature remains neutral with regard to jurisdictional claims in published maps and institutional affiliations.

(c) (i) Open Access This article is licensed under a Creative Commons Attribution 4.0 International License, which permits use, sharing, adaptation, distribution and reproduction in any medium or format, as long as you give appropriate credit to the original author(s) and the source, provide a link to the Creative Commons license, and indicate if changes were made. The images or other third party material in this article are included in the article's Creative Commons license, unless indicated otherwise in a credit line to the material. If material is not included in the article's Creative Commons license and your intended use is not permitted by statutory regulation or exceeds the permitted use, you will need to obtain permission directly from the copyright holder. To view a copy of this license, visit http://creativecommons.org/ licenses/by/4.0/.

(C) The Author(s) 2017 